\title{
Glycerate kinase of the hyperthermophilic archaeon Thermoproteus tenax: new insights into the phylogenetic distribution and physiological role of members of the three different glycerate kinase classes
}

\author{
Daniel Kehrer ${ }^{\dagger 1}$, Hatim Ahmed ${ }^{\dagger 1}$, Henner Brinkmann ${ }^{2}$ and Bettina Siebers*1
}

Address: ${ }^{1}$ Department of Biology and Geography, Institute of Biology, Microbiology I, Universität Duisburg-Essen, Universitätsstr. 5, 45117 Essen, Germany and 2Département de biochimie, Faculté de Médecine, Université de Montréal, C.P. 6128, Succ. Centre-ville, Montréal, Qc H3C 3J7, Canada

Email: Daniel Kehrer - daniel.kehrer@stud.uni-due.de; Hatim Ahmed - hatim.ahmed@stud.uni-due.de; Henner Brinkmann - henner.brinkmann@umontreal.ca; Bettina Siebers* - bettina.siebers@uni-due.de

* Corresponding author †Equal contributors

Published: 31 August 2007

BMC Genomics 2007, 8:30| doi:|0.||86/|47|-2|64-8-30|
Received: 30 January 2007

Accepted: 3I August 2007

This article is available from: http://www.biomedcentral.com/I47|-2/64/8/30I

(c) 2007 Kehrer et al; licensee BioMed Central Ltd.

This is an Open Access article distributed under the terms of the Creative Commons Attribution License (http://creativecommons.org/licenses/by/2.0), which permits unrestricted use, distribution, and reproduction in any medium, provided the original work is properly cited.

\begin{abstract}
Background: The presence of the branched Entner-Doudoroff (ED) pathway in two hyperthermophilic Crenarchaea, the anaerobe Thermoproteus tenax and the aerobe Sulfolobus solfataricus, was suggested. However, so far no enzymatic information of the non-phosphorylative ED branch and especially its key enzyme - glycerate kinase - was available. In the T. tenax genome, a gene homolog with similarity to putative hydroxypyruvate reductase/glycerate dehydrogenase and glycerate kinase was identified.

Results: The encoding gene was expressed in $E$. coli in a recombinant form, the gene product purified and the glycerate kinase activity was confirmed by enzymatic studies. The enzyme was active as a monomer and catalyzed the ATP-dependent phosphorylation of D-glycerate forming exclusively 2-phosphoglycerate. The enzyme was specific for glycerate and highest activity was observed with ATP as phosphoryl donor and $\mathrm{Mg}^{2+}$ as divalent cation. ATP could be partially replaced by GTP, CTP, TTP and UTP. The enzyme showed high affinity for D-glycerate $\left(\mathrm{K}_{\mathrm{m}} 0.02 \pm 0.01 \mathrm{mM}, \mathrm{V}_{\max }\right.$ of $5.05 \pm 0.52 \mathrm{U} / \mathrm{mg}$ protein) as well as ATP $\left(\mathrm{K}_{\mathrm{m}}\right.$ of $0.03 \pm 0.01 \mathrm{mM}, \mathrm{V}_{\max }$ of $4.4 \mathrm{I} \pm 0.04$ $\mathrm{U} / \mathrm{mg}$ protein), although at higher glycerate concentrations, substrate inhibition was observed. Furthermore, the enzyme was inhibited by its product ADP via competitive inhibition. Data bank searches revealed that archaeal glycerate kinases are members of the MOFRL (multi-organism fragment with rich leucine) family, and homologs are found in all three domains of life.

Conclusion: A re-evaluation of available genome sequence information as well as biochemical and phylogenetic studies revealed the presence of the branched ED pathway as common route for sugar degradation in Archaea that utilize the ED pathway. Detailed analyses including phylogenetic studies demonstrate the presence of three distinct glycerate kinase classes in extant organisms that share no common origin. The affiliation of characterized glycerate kinases with the different enzyme classes as well as their physiological/cellular function reveals no association with particular pathways but a separate phylogenetic distribution. This work highlights the diversity and complexity of the central carbohydrate metabolism. The data also support a key function of the conversion of glycerate to 2- or 3-phosphoglycerate via glycerate kinase in funneling various substrates into the common EMP pathway for catabolic and anabolic purposes.
\end{abstract}




\section{Background}

Modifications of the ED pathway, the semi-phosphorylative (sp) and the non-phosphorylative (np) ED pathway, have been identified in all three forms of life [1]. Initial biochemical studies in Archaea revealed the presence of the npED pathway in (hyper)thermophiles [2-8] and the spED pathway in halophiles [9]. However, a recent approach that combined comparative genomics and biochemistry identified the presence of the spED pathway probably in addition to the npED pathway - in T. tenax and $S$. solfataricus, suggesting the presence of a branched ED pathway in these hyperthermophiles. $[8,10-13]$. The hyperthermophilic anaerobe Thermoproteus tenax grows optimally around $90^{\circ} \mathrm{C}, \mathrm{pH}$. This sulphur-dependent Creanarchaeon is able to grow chemolithoautotrophically on $\mathrm{CO}_{2}$ and $\mathrm{H}_{2}$, as well as chemoorganoheterotrophically in the presence of various organic compounds such as starch, glucose, malate and methanol $[14,15]$. Therefore, T. tenax represents a perfect model organism for studying the complexity of the central carbohydrate metabolism as well as its regulation.

In the suggested branched ED pathway [10], glucose is oxidized to gluconate via glucose dehydrogenase, and gluconate is dehydrated forming 2-keto-3-deoxygluconate (KDG) by gluconate dehydratase (GAD). In the spED branch, KDG is phosphorylated via KDG kinase, the key enzyme of the spED branch, and the formed 2-keto-3deoxy-6-phosphogluconate (KDPG) is cleaved into glyceraldehyde-3-phosphate (GAP) and pyruvate by the action of the bifunctional $\mathrm{KD}(\mathrm{P}) \mathrm{G}$ aldolase, which is a key player in both ED branches. GAP is processed via the common lower shunt of the EMP (Embden-Meyerhof-Parnas) pathway, which is characterized by the presence of an unusual irreversible non-phosphorylating GAP dehydrogenase and/or GAP oxidoreductase in hyperthermophiles. These enzymes substitute for the anabolic enzyme couple $\mathrm{NADP}^{+}$-dependent GAP dehydrogenase and phosphoglycerate kinase $[11,16-18]$. In the npED branch, $\mathrm{KD}(\mathrm{P}) \mathrm{G}$ aldolase cleaves KDG into pyruvate and glyceraldehyde. Glyceraldehyde is further oxidized to form glycerate either by a $\mathrm{NAD}(\mathrm{P})^{+}$-dependent glyceraldehyde dehydrogenase $[3,19,20]$ or by a ferredoxin-dependent glyceraldehyde oxidoreductase [5,21-23]. Glycerate is phosphorylated via glycerate kinase, the key enzyme of the npED branch, forming 2-phosphoglycerate. 2-Phosphoglycerate then enters the common lower shunt of the EMP pathway yielding a second molecule of pyruvate by the action of enolase and pyruvate kinase (Fig. 1).

Enzymes of the common ED shunt (glucose dehydrogenase $[6,10,24,25]$, gluconate dehydratase $[10,26,27]$ and $\mathrm{KD}(\mathrm{P}) \mathrm{G}$ aldolase $[24,28,10])$ as well as the spED branch (KDG kinase $[10,29]$ ) have been characterized from the hyperthermophilic Archaea T. tenax and S. solfataricus.

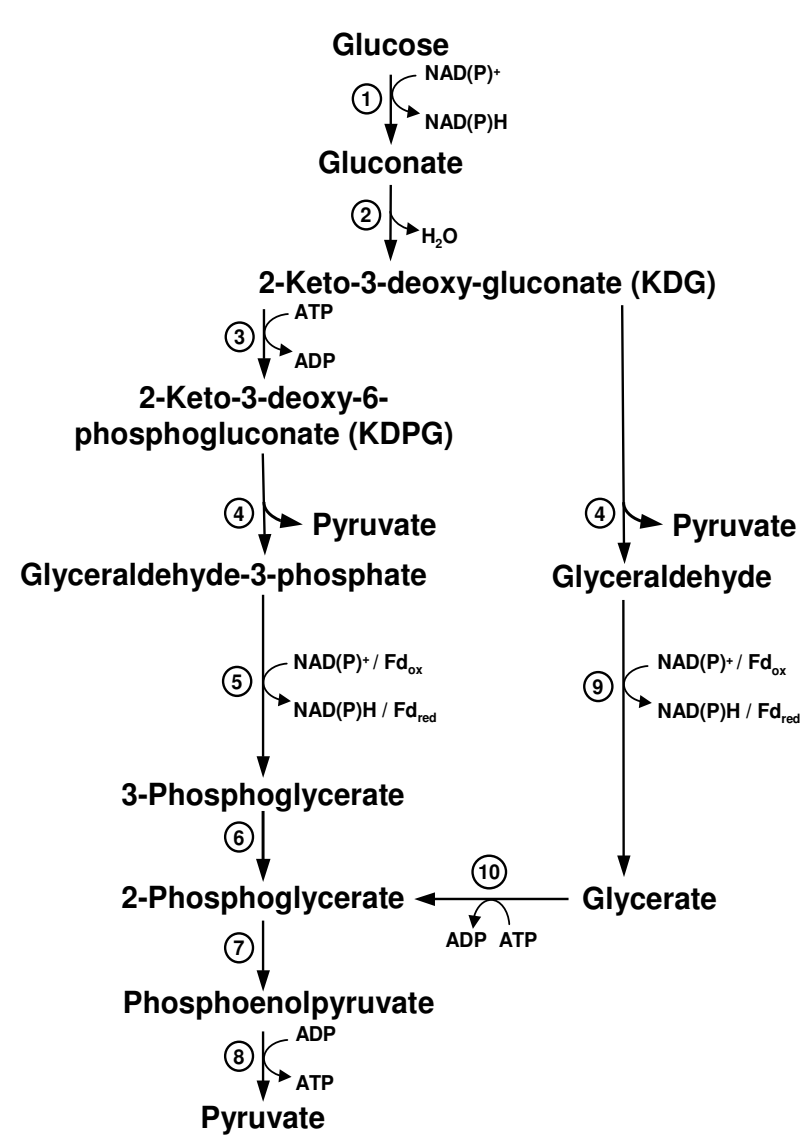

\section{Figure I}

Branched Entner-Doudoroff (ED) pathway in Thermoproteus tenax. The common ED shunt comprises the conversion of glucose into 2-keto-3-deoxygluconate (KDG), which is either phosphorylated and cleaved forming pyruvate and glyceraldehyde-3-phosphate (GAP) in the semi-phosphorylative ED branch (left side) or directly cleaved forming pyruvate and glyceraldehyde in the non-phosphorylative branch (right side). Enzyme key: I, glucose dehydrogenase; 2, gluconate dehydratase (GAD); 3, 2-keto-3-deoxygluconate (KDG) kinase; 4, 2-keto-3-deoxy-(6-phospho)gluconate $(\mathrm{KD}(\mathrm{P}) \mathrm{G})$ aldolase; 5, non-phosphorylating GAP dehydrogenase (GAPN) or GAP oxidoreductase; 6 , phosphoglycerate mutase; 7 , enolase; 8 , pyruvate kinase; 9 , aldehyde dehydrogenase or aldehyde oxidoreductase; 10, glycerate kinase.

Interestingly, these enzymes were shown to be promiscuous for glucose and galactose catabolism in S. solfataricus $[24-26,28,29]$, which relies on the ED pathway as only route for sugar degradation. In contrast, the pathway seems to be specific for glucose and is active in addition to the EMP variant in T. tenax $[6,10]$. Glyceraldehyde oxidoreductase activity has been reported in cell extracts of $T$. tenax [5]. However, no information is currently available for the key enzyme of the npED branch, glycerate kinase, in T. tenax and hyperthermophilic Archaea in general. 
Studies addressing this metabolic key reaction are expected to reveal some new important insights into the regulation and the physiological role of the branched ED pathway.

Glycerate kinases have been characterized from all domains of life: Bacteria, Eukarya and Archaea. In general, two distinct classes of glycerate kinases were identified: 3phosphoglycerate (3-PG) and 2-phoshoglycerate (2-PG) forming glycerate kinases. 3-PG forming enzymes were characterized for example in plants, fungi and different heterotrophic bacteria. 2-PG forming glycerate kinases, on the other hand, were identified and examined in animals and methylotrophic bacteria. Recently, the 2-PG forming glycerate kinases of the thermoacidophilic Euryarchaea Picrophilus torridus and Thermoplasma acidophilum were characterized and their function as key enzyme of the npED pathway in thermophiles was reported [30,32]. However, up to now little attention was given to the phylogenetic affiliation of the enzymes. Initial phylogenetic analyses published previously indicate the presence of three glycerate kinase families or groups and wrongly suggest that they share a common origin $[31,32]$.

In order to confirm the presence of the branched ED pathway in T. tenax and beyond that in other hyperthermophilic Archaea and in order to study this pathway's regulation, the gene encoding the putative glycerate kinase was cloned and the enzymatic and regulatory properties of the gene product were characterized. Here we describe the first hyperthermophilic archaeal glycerate kinase, the enzyme of Thermoproteus tenax. Moreover, new data from comparative genomics analyses as well as available biochemical information indicate a much broader distribution of the branched ED pathway in Archaea than previously assumed. Finally, the evolution of glycerate kinases was re-evaluated revealing the presence of three independent glycerate kinase classes that share no common origin: i) the glycerate kinase class I (GK I), ii) the glycerate kinase class II (GK II, MOFRL family) as well as iii) a novel glycerate kinase family related to the phosphoribulokinase/uridine kinase family, here named glycerate kinase class III (GK III). The affiliation of enzymes with the different enzyme classes, their phylogenetic distribution as well as their physiological function are discussed. This study confirms the complexity and mosaic nature of the central carbohydrate metabolic pathways in extant organisms.

\section{Results and discussion}

Combined genomics and biochemical studies suggested the presence of the branched ED pathway in Thermoproteus tenax [10]. In the genome of T. tenax, one gene homolog with high similarity to predicted glycerate kinases (COG 2379, EC 2.7.1.31) and hydroxypyruvate reductases (glyc- erate dehydrogenases) (COG 2379, EC 1.1.1.29 (NADH), EC1.1.1.81 (NAD $(\mathrm{P}) \mathrm{H}))$ was identified [8]. In order to confirm the predicted glycerate kinase activity and thus the presence of the branched ED pathway in T. tenax and to gain first insights into its regulation as well as its physiological role, the encoding gene was expressed as a recombinant protein in E. coli, purified and characterized.

\section{Cloning of the garK gene, expression and purification of the glycerate kinase from $T$. tenax}

The gene encoding the putative glycerate kinase/hydroxypyruvate reductase from T. tenax (garK, AJ621354) revealed an open reading frame of $1197 \mathrm{bp}$ coding for a polypeptide of 398 amino acids. The glycerate kinase/ hydroxypyruvate reductase homolog revealed significant overall similarity with the recently characterized glycerate kinase of the thermoacidophile P. torridus, (27\% identity, Blastp search) as well as numerous "annotated" glycerate kinases and hydroxypyruvate reductases or glycerate dehydrogenases in all three domains of life. The garK gene was cloned and expressed in E. coli BL21 (DE3) using the pET expression vector system. The recombinant enzyme was enriched from $E$. coli crude extract by heat precipitation at $80^{\circ} \mathrm{C}$ for 30 minutes. Further purification was achieved by Q-sepharose, phenyl sepharose and gel filtration (Fig. 2). From $10 \mathrm{~g}$ wet cells of recombinant E. coli, $2.72 \mathrm{mg}$ of homogenous glycerate kinase with a specific activity of 4.6 $\mathrm{U} / \mathrm{mg}$ protein was recovered.

The glycerate kinase of $T$. tenax migrated as a single band on SDS-PAGE with an apparent molecular mass of $44 \mathrm{kDa}$ (Fig. 2), corresponding well to the calculated mass of 42.4 $\mathrm{kDa}$. The molecular mass of the native enzyme was determined by gel filtration on a HiLoad 26/60 Superdex 200 prep grade column and revealed $48.3 \pm 1.1 \mathrm{kDa}$, indicating a monomeric structure for the glycerate kinase of $T$. tenax. A monomeric structure was also reported for the characterized Hyphomicrobioum methylovorum GM2 glycerate kinase [33] and the enzyme of T. acidophilum [30]. Interestingly, biochemical data suggest a dimeric structure for the glycerate kinase of $P$. torridus as well as Thermotoga maritima [32,34], although analysis of the crystallographic packing of the T. maritima enzyme (TM1585) indicates a monomeric structure [34]. Also many plant enzymes (e.g. Brassica campestris [35], spinach leaf [36]), which, however, as discussed later are members of a different glycerate kinase class, exhibit a monomeric structure.

\section{Enzymatic and regulatory properties of the glycerate kinase from $T$. tenax}

Glycerate kinase activity was determined in a discontinuous assay at $70^{\circ} \mathrm{C}$ by coupling the formation of 2-phosphoglycerate with NADH oxidation in the presence of enolase, pyruvate kinase and L-lactate dehydrogenase. Glycerate kinase catalyzed the ATP-dependent phosphor- 
ylation of D-glycerate yielding 2-phosphoglycerate. No formation of 3-phosphoglycerate was observed in response to the addition of phoshoglycerate mutase to the assay. The enzyme showed activity only in the presence of ATP and $\mathrm{Mg}^{2+}$. No activity was detected in controls without protein or without the (co-)substrates D-glycerate, ATP or both D-glycerate and ATP. The enzyme showed no hydroxypyruvate reductase activity either in the presence of $\mathrm{NADH}+\mathrm{H}^{+}$or $\mathrm{NADPH}+\mathrm{H}^{+}$.

The 2-glycerate kinase activity was measured in the presence of different substrate and co-substrate concentrations. Strikingly, the enzyme was inhibited at higher glycerate concentrations (Fig. 3) and apparent $\mathrm{K}_{\mathrm{m}}$ - and $\mathrm{V}_{\text {max }}$-values for glycerate $(0.02 \pm 0.01 \mathrm{mM}, 5.05 \pm 0.52 \mathrm{U} /$ mg protein, D-glycerate at concentrations below $0.3 \mathrm{mM}$ ) and for ATP $\left(\mathrm{K}_{\mathrm{m}}\right.$ of $0.03 \pm 0.01 \mathrm{mM}, \mathrm{V}_{\max }$ of $4.41 \pm 0.04 \mathrm{U} /$ mg protein) at $70^{\circ} \mathrm{C}$ were estimated. No substrate inhibition was observed for the enzymes of $P$. torridus, $T$. acidophilum, and H. methylovorum. As shown in Table 1, the T. tenax enzyme exhibits a higher substrate affinity, however, the specific activity is significantly reduced in comparison to the glycerate kinases of $P$. torridus and H. methylovorum. This is reflected in an about 6 or 7 -fold (glycerate) and 5 or 9-fold (ATP) reduced catalytic efficiency $\left(\mathrm{k}_{\mathrm{cat}} / \mathrm{K}_{\mathrm{m}}\right.$-values, Tab. 1) of the hyperthermophilic enzyme compared to $P$. torridus and $H$. methylovorum, respectively. The glycerate kinase of $T$. acidophilum shows a similar catalytic efficiency for glycerate, only for ATP it is slightly (2.3-fold) increased.

The ability of the T. tenax glycerate kinase to phosphorylate other compounds than D-glycerate was tested in a discontinous assay at $70^{\circ} \mathrm{C}$ by monitoring the formation of ADP from the ATP-dependent phosphorylation of substrate via pyruvate kinase and lactate dehydrogenase. The following compounds were substituted for D-glycerate: the stereoisomer L-glycerate, sugar acids (galactonate, gluconate, malate, pyruvate, lactate), glyceraldehyde, glycerol, serine and phosphorylated intermediates (3-

Table I: Comparison of kinetic and biochemical properties from characterized class II glycerate kinases (MOFRL family)

\begin{tabular}{|c|c|c|c|c|c|}
\hline & & \multicolumn{3}{|c|}{ Archaea } & \multirow{3}{*}{$\begin{array}{c}\text { Bacteria } \\
\text { H. methylovorum } \\
\end{array}$} \\
\hline & & \multirow{2}{*}{$\begin{array}{c}\text { Crenarchaea } \\
\text { T. tenax }\end{array}$} & \multicolumn{2}{|c|}{ Euryarchaea } & \\
\hline & & & P. torridus ${ }^{2}$ & T. acidophilum ${ }^{3}$ & \\
\hline \multicolumn{2}{|c|}{ Growth optimum $\left({ }^{\circ} \mathrm{C}\right)$} & 90 & 60 & 59 & 28 \\
\hline \multicolumn{6}{|c|}{ Molecular mass } \\
\hline \multicolumn{2}{|c|}{ Subunit $(k D a)$} & 44 & 50 & 45 & 52 \\
\hline \multicolumn{2}{|c|}{ Native $(k D a)$} & 48,3 & 95 & 49,3 & 41 \\
\hline \multicolumn{2}{|c|}{ Calculated (kDa) } & 42,4 & 46,6 & 45,8 & $(46.5)^{5}$ \\
\hline \multicolumn{2}{|c|}{ Oligomeric structure } & Monomer & Dimer & Monomer & Monomer \\
\hline \multicolumn{6}{|c|}{ Kinetic Parameters } \\
\hline \multirow[t]{4}{*}{ D-Glycerate } & $\mathrm{K}_{\mathrm{m}}(\mathrm{mM})$ & $(0.02)^{6}$ & 0,34 & $(0.56)^{7}$ & 0,13 \\
\hline & $\mathrm{V}_{\max }\left(\mathrm{U} \mathrm{mg}^{-1}\right)$ & $(5.05)^{6}$ & 435 & $(118)^{7}$ & 181 \\
\hline & $\mathrm{k}_{\text {cat }}\left(\min ^{-1}\right)$ & 214 & $2027 \mid$ & 5404 & 8417 \\
\hline & $\mathrm{k}_{\mathrm{cat}} / \mathrm{K}_{\mathrm{m}}\left(\mathrm{min}^{-1} \mathrm{mM}^{-1}\right)$ & 8913 & 59621 & 9651 & 64742 \\
\hline \multirow[t]{4}{*}{ ATP } & $\mathrm{K}_{\mathrm{m}}(\mathrm{mM})$ & $(0.03)^{6}$ & 0,51 & $(0.23)^{7}$ & 0,13 \\
\hline & $\mathrm{V}_{\max }\left(\mathrm{U} \mathrm{mg}^{-1}\right)$ & $(4.4 I)^{6}$ & 432 & $(118)^{7}$ & 181 \\
\hline & $\mathrm{k}_{\mathrm{cat}}\left(\mathrm{min}^{-1}\right)$ & 187 & 20131 & 5404 & 8417 \\
\hline & $\mathrm{k}_{\mathrm{cat}} / \mathrm{K}_{\mathrm{m}}\left(\mathrm{min}^{-1} \mathrm{mM}^{-1}\right)$ & 7187 & 39473 & 16889 & 64742 \\
\hline \multicolumn{2}{|c|}{ Reaction product } & 2-PG & 2-PG & 2-PG & 2-PG \\
\hline \multicolumn{2}{|c|}{ Temperature optimum $\left({ }^{\circ} \mathrm{C}\right)$} & 90 & 60 & 70 & 50 \\
\hline \multicolumn{6}{|c|}{ Substrate specificity (\%) } \\
\hline \multicolumn{2}{|l|}{ L-Glycerate } & 30 & 34 & nd & 13 \\
\hline \multicolumn{6}{|c|}{ Phosphate donor specificity (\%) } \\
\hline \multicolumn{2}{|l|}{ ATP } & 100 & 100 & 100 & 100 \\
\hline \multicolumn{2}{|l|}{ GTP } & 20 & 37 & $0-4$ & 59 \\
\hline \multicolumn{2}{|l|}{ CTP } & 16 & 24 & $0-4$ & 59 \\
\hline \multicolumn{2}{|l|}{ UTP } & 10 & 39 & $0-4$ & 64 \\
\hline \multicolumn{2}{|l|}{ TTP } & 16 & nd & nd & nd \\
\hline \multicolumn{6}{|c|}{ Metal ion specificity (\%) } \\
\hline \multicolumn{2}{|l|}{$\mathrm{Mg}^{2+}$} & 100 & 100 & 100 & 100 \\
\hline \multicolumn{2}{|l|}{$\mathrm{Co}^{2+}$} & 56 & 11 & 8 & 75 \\
\hline \multicolumn{2}{|l|}{$\mathrm{Mn}^{2+}$} & 59 & II & 10 & 72 \\
\hline \multicolumn{2}{|l|}{$\mathrm{Ni}^{2+}$} & 30 & 25 & 0 & 29 \\
\hline \multicolumn{2}{|l|}{$\mathrm{Ca}^{2+}$} & 15 & nd & 0 & 0 \\
\hline Inhibition $b$ & & + & nd & nd & + \\
\hline
\end{tabular}

'this study; ${ }^{2}[32] ;{ }^{3}[30]{ }^{4}$ [33]; 5 since no information of the encoding gene is available, the mean value of subunit and native molecular mass was formed and used for the calculation of the $\mathrm{k}_{\mathrm{cat}} / \mathrm{K}_{\mathrm{m}}$ value; ${ }^{6}$ since glycerate inhibition is observed for the $T$. tenax enzyme the estimated values for glycerate concentration up to $0.3 \mathrm{mM}$ are given; 7determined for DL-Glycerate; nd, not determined; +, detected. 


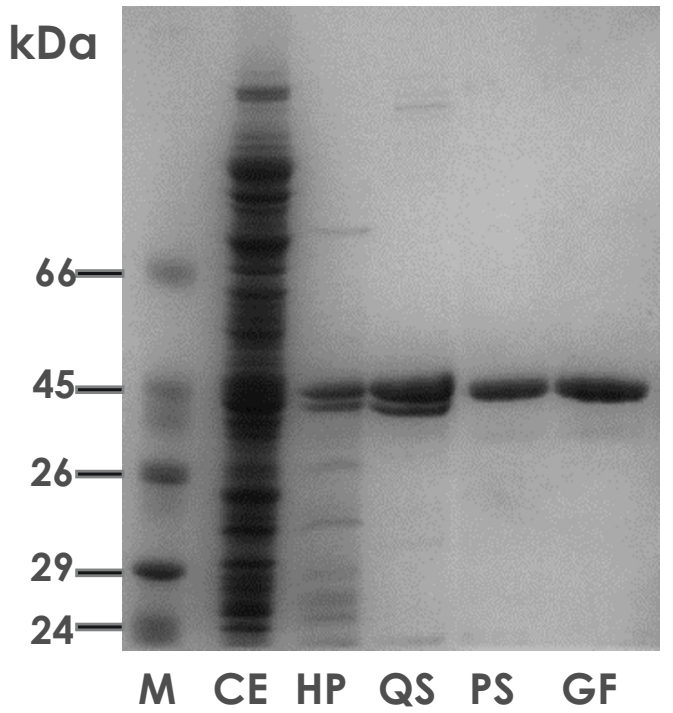

\section{Figure 2}

Purification of the recombinant class II glycerate

kinase of T. tenax. SDS-PAGE of the recombinant expression and purification of $T$. tenax glycerate kinase. Lanes with crude cell extracts (CE, $20 \mu \mathrm{g}$ ), soluble fractions after heat precipitation (HP, $10 \mu \mathrm{g}$ ) and after purification by $\mathrm{Q}$ sepharose (QS), phenyl sepharose (PS) and gel filtration (GF) (5 $\mu \mathrm{g})$ are shown. ' $M$ ' refers to the protein marker, Dalton Mark VII-L (Sigma)).

phosphoglycerate, glyceraldehyde 3-phosphate (GAP)). The enzyme is absolutely specific for glycerate as phosphoryl acceptor. Like the enzymes of $P$. torridus [32], $H$. methylovorum [33] and plant [37] glycerate kinases described so far, the enzyme showed higher activity with D-glycerate (100\%) and only low activity with L-glycerate (30\%) (Tab. 1).

The T. tenax glycerate kinase has a temperature optimum at $90^{\circ} \mathrm{C}(100 \%$ activity $)$, correlating well with its growth optimum (around $90^{\circ} \mathrm{C}$ ). At $70^{\circ} \mathrm{C}$ only $55 \%$ and at $50^{\circ} \mathrm{C}$ only $15 \%$ residual activity were observed.

The specificity of the enzyme for phosphoryl donors (5 $\mathrm{mM}$ ) was tested for ATP, CTP, GTP, TTP, UTP, ADP as well as $\mathrm{PP}_{\mathrm{i}}$ and polyphosphates $\left(\mathrm{P}_{3}, \mathrm{P}_{5}\right.$ and $\left.\mathrm{P}_{25}\right)$. The enzyme exhibited highest activity with ATP, although ATP could be partially replaced by CTP, GTP, TTP and UTP $(16 \%$, $20 \%, 16 \%$ and $10 \%$ activity, respectively). No activity was observed with $\mathrm{ADP}, \mathrm{PP}_{\mathrm{i}}$ and polyphosphates.

The glycerate kinase of $T$. tenax required divalent metal ions for activity and the highest activity was observed in

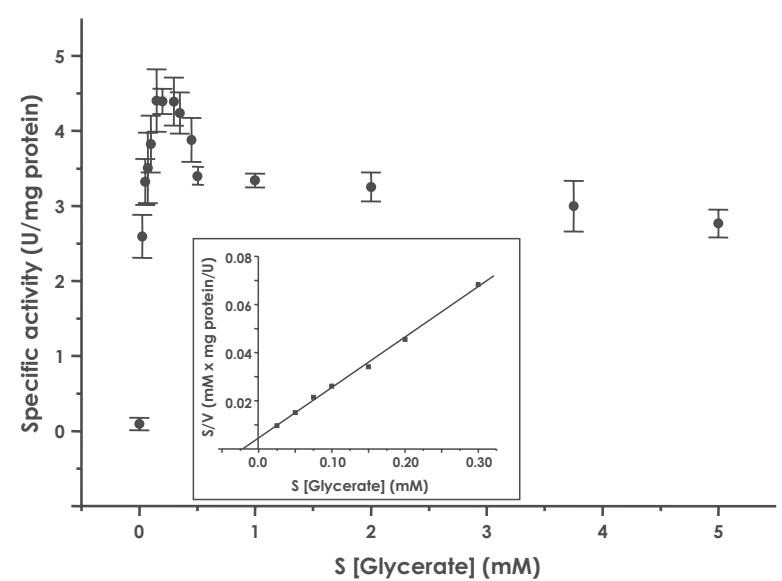

Figure 3

Kinetic properties of the class II glycerate kinase of $T$. tenax. The glycerate kinase activity was determined in a discontinuous assay at $70^{\circ} \mathrm{C}$ by coupling the formation of 2phosphoglycerate with NADH oxidation via enolase, pyruvate kinase and lactate dehydrogenase. The dependence of the specific enzyme activity on the glycerate concentration is shown. The enzyme is inhibited at higher glycerate concentrations. The insert shows the linear transformation according to Hanes for glycerate concentrations up to $0.3 \mathrm{mM}$.

the presence of $20 \mathrm{mM} \mathrm{Mg}^{2+}$. Activity was inhibited by the addition of EDTA $(40 \mathrm{mM})$. $\mathrm{Co}^{2+}, \mathrm{Mn}^{2+}$ and $\mathrm{Ni}^{2+}$ (all 5 $\mathrm{mM})$ and $\mathrm{Ca}^{2+}(2 \mathrm{mM})$ could partially replace $\mathrm{Mg}^{2+}(56 \%$, $59 \%, 30 \%$ and $15 \%$ activity, respectively). No activity was detected in the presence of $\mathrm{Cu}^{2+}$ and $\mathrm{Fe}^{2+}$ at $0.2,2,5$ and $20 \mathrm{mM}$. Thus, in respect of cosubstrate specificity and dependence on metal ions, the enzyme of $T$. tenax resembles the enzymes of $P$. torridus and $H$. methylovorum and plant glycerate kinases described previously $[32,33,38]$ (Tab. 1). Monovalent ions $\left(\mathrm{K}^{+}\right.$and $\left.\mathrm{NH}_{4}{ }^{+}\right)$, which were reported to activate the $H$. methylovorum glycerate kinase [33], showed no effect on the T. tenax and P. torridus enzyme.

Effector studies were performed in the presence of nonsaturating concentrations of D-glycerate $(50 \mu \mathrm{M})$ and non-saturating $(50 \mu \mathrm{M})$ and saturating $(5 \mathrm{mM})$ concentrations of ATP. The reaction rate of T. tenax glycerate kinase showed no significant alteration by the following intermediates ( 1 and $10 \mathrm{mM}$ ): AMP, intermediates of the EMP pathway (glucose, glucose 6-phosphate, fructose 1,6bisphosphate, fructose 6-phosphate, dihydroxyacetone phosphate, GAP, 3-phosphoglycerate, lactate), the branched ED pathway (galactonate, gluconate, KDG), glycogen metabolism (glucose 1-phosphate) and the citric 
acid cycle (citrate, isocitrate, $\alpha$-ketoglutarate, succinate, fumarate, malate). The reaction product ADP showed an inhibitory effect on the glycerate kinase activity. In the presence of non-saturating concentrations of ATP, the inhibition by ADP was much higher suggesting competitve inhibition (non-saturating ATP: 76\%, 39.1\%, $8.2 \%$ and saturating ATP: $93.2 \%, 87.3 \%, 42 \%$ activity of control at concentrations of $0.01,0.1$, and $1 \mathrm{mM}$ ADP, respectively; the average over two independent measurements is given). A similar inhibition by ADP is also reported for the H. methylovorum enzyme [33]. For the $P$. torridus and T. acidophilum enzyme respective studies were not performed [32].

In summary, the gene product of the garK gene possesses exclusively 2-glycerate kinase activity, and no 3-glycerate kinase or hydroxypyruvate reductase activity was detected. The first characterized archaeal hyperthermophilic enzyme exhibits common features with the well characterized enzymes of $P$. torridus, T. acidophilum and H. methylovorum such as (co)substrate specificity and metal ion dependence. At the same time, it also shows some unique characteristics such as its inhibition by glycerate and its hyperthermophilic properties (Tab. 1). The physiological significance of the inhibition by glycerate is unknown, since information about the cellular concentrations of glycerate in $T$. tenax is currently unavailable. The key enzyme of the non-phosphorylative branch of the ED pathway in T. tenax seems to be no subject of broad regulatory control, at least for the effectors tested, but seems to be regulated by the energy charge of the cell probably via competitve (product) inhibition by ADP.

\section{Distribution of the branched ED pathway in Archaea}

New comparative genomics based data [12,13] and available biochemical information revealed a much broader distribution of the branched pathway in Archaea than previously assumed (Tab. 2). As supported by biochemical and phylogenetic data, the branched ED pathway is not only present in hyperthermophilic Archaea (e.g. T. tenax, Sulfolobales) but represents the pathway for sugar degradation in thermoacidophilic Archaea (e.g. Thermoplasmatales) and Haloarchaea, with the only exception of Halobacterium sp. NRC-1.

In thermoacidophiles the specific enzymes of the npED branch glyceraldehyde dehydrogenase (P. torridus [19], T. acidophilum $[19,39])$ as well as the glycerate kinase (P. tor-

Table 2: Phylogenetic distribution of ED key enzymes in Archaea utilizing the ED pathway

\begin{tabular}{|c|c|c|c|c|c|c|}
\hline \multirow{2}{*}{$\begin{array}{l}\text { Enzyme } \\
\text { Enzyme family }\end{array}$} & & \multirow{2}{*}{$\begin{array}{c}\text { GAD } \\
\text { MR-MLE }\end{array}$} & \multirow{2}{*}{$\begin{array}{c}\text { KD(P)GA } \\
\text { NAL }\end{array}$} & \multirow{2}{*}{$\begin{array}{c}\text { GK II } \\
\text { MORFL }\end{array}$} & \multicolumn{2}{|c|}{ KDGK } \\
\hline & & & & & PfkB & $\begin{array}{c}\mathrm{BadF} / \mathrm{BadG} / \mathrm{BcrA} / \\
\mathrm{BcrD}\end{array}$ \\
\hline EC & & 4.2.1.39 & 4.1.2.- & 2.7.1.31 & 2.7 .1 .45 & 2.7.1.59 \\
\hline COG & & 4948 & 0329 & 2379 & 0524 & 2971 \\
\hline \multicolumn{7}{|l|}{ Crenarchaea } \\
\hline Thermoproteales & TTX & $\frac{1156}{A] 621281}$ & $\frac{1156 a}{A J 621282}$ & $\frac{0788}{A) 621345}$ & $\frac{1157}{A \sqrt{621283}}$ & \\
\hline \multirow[t]{3}{*}{ Sulfolobales } & SACl & 0885 & 0225 & 0113 & 0226 & \\
\hline & SSO & $\underline{3198}$ & $\underline{3197}$ & 0666 & $\underline{3195}$ & \\
\hline & STO & 2366 & 2479 & 2037 & 2478 & \\
\hline \multicolumn{7}{|l|}{ Euryarchaea } \\
\hline \multirow[t]{4}{*}{ Halobacteriales } & HMA & 3069 & 0207 & 7015 & 0545 & \\
\hline & $\mathrm{HQ}$ & $24 I 2 A$ & I507A & I667A & $1455 \mathrm{~A}$ & \\
\hline & VNG & 0442G & 0444G & - & $0158 \mathrm{G}$ & \\
\hline & $\mathrm{NPH}$ & 0998A & $1490 \mathrm{~A}$ & $1162 \mathrm{~A}$ & $3184 \mathrm{~A}$ & \\
\hline \multirow{4}{*}{ Thermoplasmatales } & PTO & 0485 & 1026 & $\underline{1442}$ & - & 0011 \\
\hline & TA & 0085 & 0619 & $\underline{0453 \mathrm{~m}}$ & - & $\underline{0122}$ \\
\hline & TVN & 179275 & 663048 & 797109 & - & 204668 \\
\hline & FAC & 0084 & 1067 & 0418 & - & 1438 \\
\hline
\end{tabular}

Blast searches were performed with the characterized T. tenax enzymes or the T. acidophilum KDG kinase. The gene numbering is according to [67]. The table represents an update of recently published work referring to the phylogenetic distribution of genes involved in glucose and pentose metabolism in Archaea [13].

Characterized enzymes are underlined. Abbreviations: GAD, gluconate dehydratase; KD(P)GA, 2-keto-3-deoxy-(6-phospho)-gluconate aldolase; GK II, glycerate kinases class II; KDGK, 2-keto-3-deoxygluconate kinase. EC, Enzyme Commission; COG, Clusters of Orthologous Groups. MRMLE, mandelate racemase/muconate lactonizing enzyme subgroup of the enolase superfamily; NAL, $\mathrm{N}$-acetylneuraminate lyase superfamily; MORFL, multi-organism fragment with rich leucine family; PfkB, ribokinase-like superfamily, pfkB family carbohydrate kinase; BadF/BadG/BcrA/BcrD, BadF/ BadG/BcrA/BcrD ATPase family

FAC: Ferroplasma acidarmanus ferl, HMA: Haloarcula marismortui ATCC 43049, HQ: Haloquadratum walsbyi DSMI6790, NPH: Natronomonas pharaonis DSM 2160 , PTO: Picrophilus torridus DSM 9790, SACI: Sulfolobus acidocaldarius DSM 639, SSO: Sulfolobus solfataricus P2, STO: Sulfolobus tokodaii str. 7, TA: Thermoplasma acidophilum DSM I 728, TTX: Thermoproteus tenax, TVN: Thermoplasma volcanium GSSI, VNG: Halobacterium sp. NRC-I 
ridus [32], T. acidophilum [30]) have been characterized recently. In addition, the presence of the spED branch was demonstrated by the identification of a novel KDG kinase in T. acidophilum [39], which is not related to the characterized enzymes of T. tenax and S. solfataricus (ribokinaselike superfamily, pfkB family carbohydrate kinase, PF00294), but is a member of the BadF/BadG/BcrA/BcrD ATPase family (PF01869). Homologs of the new KDG kinase were identified in all members of the Thermoplasmatales with available genome sequence information. In Haloarchaea the presence of glycerate kinase homologs in Haloarcula marismortui, Haloquadratum walsbyi and Natronomonas pharaonis suggests the presence of the branched ED pathway rather than the assumed spED pathway. Therefore the branched ED pathway - rather than the semi- or non-phosphorylative ED pathway seems to be common for sugar degradation in Archaea that utilize the ED pathway.

\section{Phylogenetic analyses}

\section{Glycerat kinase class II (MOFRL family)}

Data bank searches (BlastX, BlastP) revealed sequences homologous to the glycerate kinase of T. tenax in all three domains of life: Bacteria, Eukarya and Archaea. In Archaea, glycerate kinase homologs were identified in about half (19 of 35) of the sequenced genomes (Tab. 2, Fig. 4, Fig. 6). Beside Archaea that utilize the ED pathway for sugar degradation (Tab. 2) homologs were also identified in the genomes of Aeropyrum pernix (APE0996), Pyrobaculum aerophilum (PAE1309), Thermofilum pendens (TPE0207), Metallosphaera sedula (MSED0161) and in Thermococcales (Pyrococcus horikoshii (PHO0495), P. abyssi (PAB1021), P. furiosus (PFU0024), Thermococcus kodakarensis (TKO1893)). No glycerate kinase homologs were identified in the genomes of Halobacterium sp. NRC1, Pyrobaculum islandicum, Archaeoglobus fulgidus, Nanoarchaeum equitans and Methanogens (Methanocaldococcus jannaschii, Methanococcoides burtonii, Methanococcus maripaludis, Methanoculleus marisnigri, Methanopyrus kandleri, Methanosaeta thermophila, Methanosarcina acetivorans, $M$. barkeri, M. mazei, Methanosphaera stadtmanae, Methanospirillum hungatei, Methanothermobacter thermautotrophicus).

Whereas all archaeal and eukaryal organisms harbor only one gene encoding glycerate kinase, paralogous genes that originated in gene duplications and/or horizontal gene transfer (HGT) were found in several bacteria (e.g. Ralstonia solanacearum, Sinorhizobium meliloti (Fig. 7)). All homologs are characterized by the conserved C-terminal MORFL (multi-organism fragment with rich leucine) domain (residues 304-410 of the glycerate kinase of $T$. maritima, TM1585). For the identification of conserved amino acid patterns sequences of all identified members of class II glycerate kinases (MOFRL family) were analyzed by PRATT $2.1[40,41]$ revealing one conserved motif (D-
$\mathrm{X}(0,2)$-G-X(0,1)-D-[GP]-X(4)-[APS]-[ACDGST] (residues 322-332 of the T. tenax glycerate kinase: DGLDGNTGVAG).

In order to analyze the phylogenetic relationship between the GK II members, we aligned 135 sequences. An overview of their relationships is shown in form of a cartoon (Fig. 5). From this group 56 sequences were selected, which adequately represent the original diversity. After the elimination of highly divergent regions, a total of 169 amino acid residues were used for the construction of the phylogenetic tree shown in Fig. 6. Phylogenetic analyses based on Maximum Likelihood resulted in a complex tree topology with three major clades. Bootstrap analyses show a low support for all basal branches.

Clade I consists essentially of archaeal homologs with a few basal branching bacteria. Within this group several lineages display a pronounced acceleration, namely the Thermoplasmatales and the Sulfolobales together with Thermoproteus. More precisely, the archaeal clade I is divided in two lineages: one with euryarchaeal (Thermoplasmatales), crenarchaeal as well as two bacterial homologs (Candidatus kuenenia, Syntrophus aciditrophicus) and a second lineage with euryarchaeal (Pyrococcus sp.) and again two bacterial homologs(T. maritima, Alkaliphilus metalliredigenes).

The second clade consists exclusively of animals. It represents the only basal branch that is weakly supported. The clade II is divided in a major group of vertebrates, an echinoderm and several insects, which are separated from the very fast-evolving nematodes. Since it is highly likely that these bilaterian animals form a monophyletic group, this observation reveals the limited resolving power of the data set and supports the view that the other groups are substantially older than the animals.

The third clade consists almost exclusively of bacterial sequences and represents the major group of bacterial homologs. However, it includes two haloarchaeal sequences possibly due to a HGT event with a high GCGram positive. This group represents a fair amount of the bacterial diversity (ten deeply branching lineages/phyla). Nevertheless, the great majority of the sequenced bacterial genomes do not contain homologous sequences.

The presence of bacterial and archaeal sequences in the first clade can be interpreted in two different ways. Either there was an early gene duplication event that created two copies in Archaea and Bacteria and subsequently these copies were lost in most lineages, or this gene was originally present in Archaea and at least two HGT events from Archaea to Bacteria created the current distribution. The phylogenetic tree contains representatives of all three 


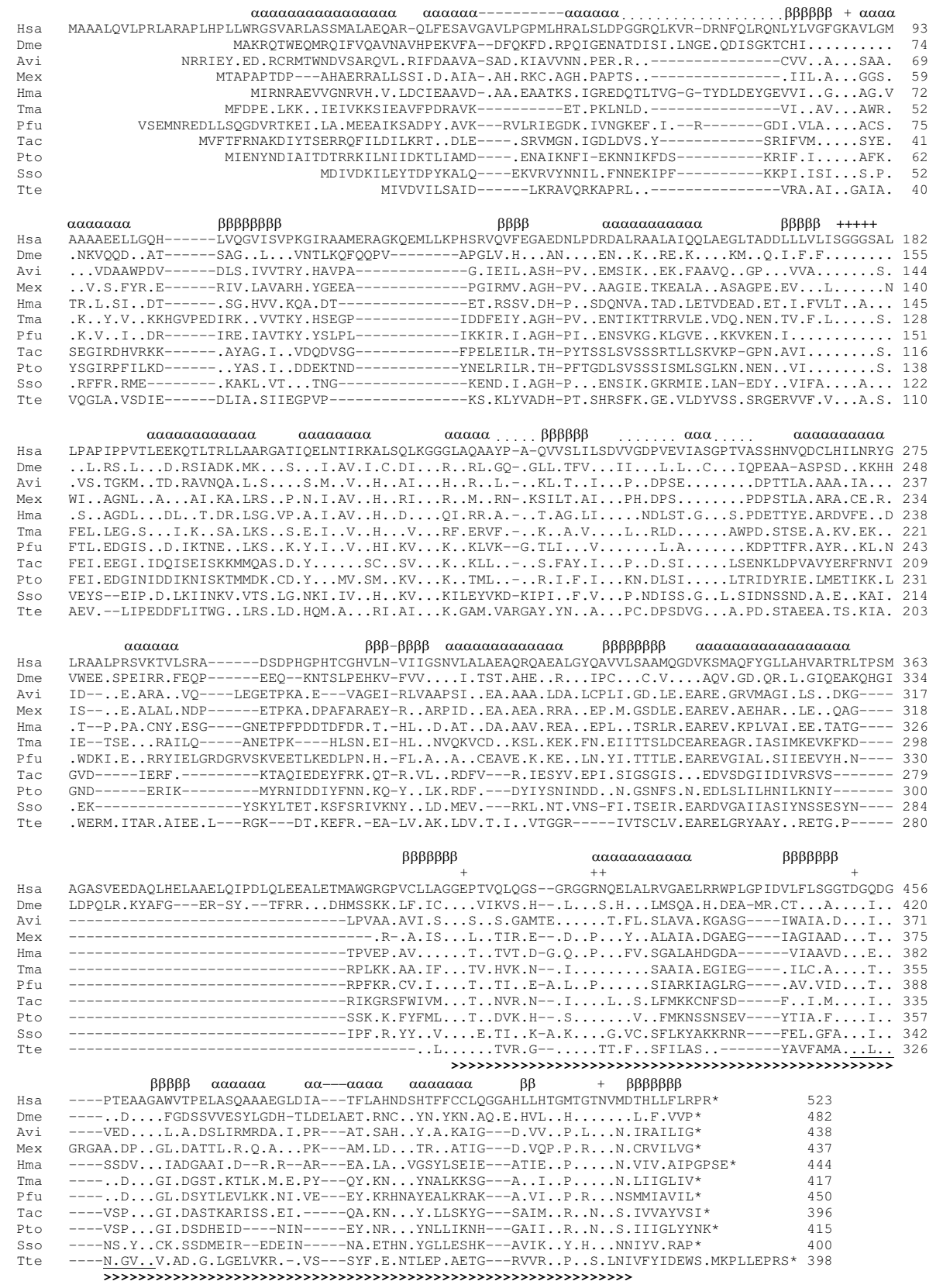

Figure 4

Multiple sequence alignment of class II glycerate kinases (MOFRL family). The determined secondary structure of the Thermotoga maritima enzyme is shown above the sequences and the catalytic sites are marked $(+)$. Amino acids identical to the first sequence are replaced by a dot; this allows the simple visualization of conserved and divergent regions. The determined consensus motif (PRATT, (D-X(0,2)-G-X(0,I)-D-[GP]-X(4)-[APS]-[ACDGST] (residues 322-332 of the T. tenax glycerate kinase)) is underlined and the MOFRL domain (T. maritima residue 304-4I0) is indicated by a bold " $>$ "sign. Abbreviations: Avi, Agrobacterium vitis; Dme, Drosophila melanogaster; Hma, Haloarcula marismortui; Hsa, Homo sapiens; Mex, Methylobacterium extorquens; Pfu, Pyrococcus furiosus; Pto, Picrophilus torridus; Sso, Sulfolobus solfataricus; Tac, Thermoplasma acidophilum; Tma, Thermotoga maritima; Tte, Thermoproteus tenax. 


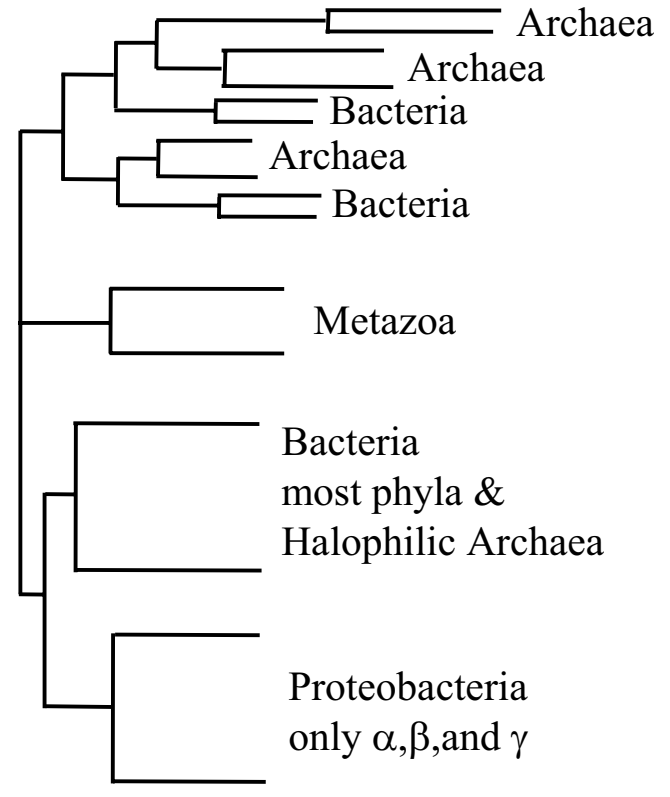

\section{Figure 5 \\ Phylogenetic analyses of class II glycerate kinases \\ (MOFRL family). Cartoon illustrating the global tree topol- ogy. Best Maximum Likelihood trees are shown in Fig. 6 and 7.}

domains of life. Consequently, it seems likely that the glycerate kinase is truly universal. This notion is supported by the fact that, despite the presence of possible HGT events at a later time, the three domains are essentially discrete. One of the lineage-specific HGT events is found in the case of the high GC-Gram positive Rubrobacter xylanophilus. This bacterium likely represents the donor lineage (Clade III) for the glycerate kinase enzymes present in the two extreme halophilic Archaea Haloarcula marismortui and Natronomonas pharaonis (Euryarchaea). No homolog was identified in the closely related Halobacterium NRC-1 genome. Further evidence for HGT events between Archaea and Bacteria in the context of thermoadaptation was demonstrated for the hyperthermophile $T$. maritima [42].

Within the bacterial clade, there is a group that is limited to more closely related proteobacterial sequences $(\alpha-, \beta-$, $\gamma$-group). The Maximum Likelihood phylogenetic tree of this group is shown in Fig 7. It is based on 56 sequences and 374 amino acid residues. Since these sequences are much closer related, there are about two times the number of positions that can be used in the phylogenetic analyses. The proteobacterial sequences are divided in two basic lineages. One of them consists exclusively of $\alpha$-Proteobac- teria and a mixed group of $\alpha-, \beta$ - and $\gamma$-Proteobacteria. In Bacteria - in contrast to Eukarya and Archaea - several species were identified with two or multiple glycerate kinase isoenzymes, representing examples of early (e.g. Ralstonia solanacearum) or more recent gene duplications (e.g. Sinorhizobium meliloti). The mosaic picture in extant Proteobacteria might therefore represent the result of a complex mixture of gene duplications with subsequent differential losses and/or potential lateral gene transfer elements.

\section{Three distinct glycerate kinase classes}

In contrast to previous reports [31,32], PSI Blast analyses revealed that members of the glycerate kinase class II (MOFRL family) show no similarity to members either of the bacterial glycerate kinase class I (GK I) or the recently identified novel kinase family (here named glycerate kinase class III, GK III) [31]. Therefore, known glycerate kinases divide in three distinct, unrelated glycerate kinase classes and seem to represent examples of independent (non-homologous) functional evolution. Interestingly, PSI Blast analyses of class III glycerate kinases revealed a diverse superfamily with enzymes that catalyze substantially different enzyme reactions such as glycerate kinase, phosphoribulokinase (EC 2.7.1.19), panthotenate kinase (EC 2.7.1.33), uridine kinase (EC 2.7.1.48) and are involved in cell division (cell division recognition particle). These data suggest that class III glycerate kinases are members of the diverse phosphoribulokinase/uridine kinase family (PF00485, nucleoside/nucleotide kinase (NK) superfamily cd02019) within the P-loop kinases, which phosphorylate all kind of different substrates [43].

The crystal structures of three glycerate kinases, one GK class I (Neisseria meningitidis (PDB $\mid \underline{106})$ ) and two GKs class II (MOFRL family, Pyrococcus horikoshii (PH0495; $\mathrm{PDB} \mid \underline{1 \times 3 l}, T$. martima (TM1585, PDB $\mid \underline{2 \mathrm{~b} 8 \mathrm{n}}),[34])$ are established. As reported previously by Schwarzenbacher et al. [34] structural similarity search revealed no significant structural similarity between the two glycerate kinase structures of $N$. meningitides (class I) and T. maritima (class II). So far no glycerate kinase class III structure is available. However, several structures of different P-loop kinases have been established, which are structurally unrelated to class I or II glycerate kinases. Therefore, the glycerate kinases of A. thaliana and S. cerevisiae represent a third class of glycerate kinases. In summary available protein structures reveal three different structural classes of glycerate kinases, which are structurally unrelated and thus evolutionarily distinct.

\section{Physiological function and affiliation of characterized enzymes with the three different glycerate kinase classes} The identification of three distinct glycerate kinase classes raises questions about the affiliation of previously charac- 
terized enzymes with the different enzyme classes and more generally about the distribution and physiological function in extant organisms (Tab. 3, Fig. 8). Respective analyses remain difficult since many biochemical studies go back to the 1950-1970s and often the genes encoding these enzymes were not identified.

Members of the class II glycerate kinases (MOFRL family, PF05161; GckA/TtuD-like family (PDB: 1o0u, SCOP)) were identified in all three domains of life (19 Archaea, 75 Bacteria, 16 Eukarya; IPR 007835). They represent the only glycerate kinases identified in Archaea and animals (Metazoa; vertebrates, echinoderm, insects, nematodes). In Bacteria a preferred presence in $\alpha-, \gamma$ - and $\delta$-Proteobacteria is observed. The glycerate kinase of $T$. tenax, the first characterized archaeal hyperthermophilic enzyme (this study), and of the thermoacidophiles $P$. torridus [32] and T. acidophilum [30] represent the only archaeal enzymes characterized so far. Several bacterial and eukaryal members have been characterized previously, although their affiliation with a new enzyme classes was not considered.

In Bacteria, class II glycerate kinase has been identified in several facultative methylotrophes, where the enzyme is a constituent of the serine cycle for conversion of C1-compounds (e.g. methane, methanol) in C3-compounds. Glycerate kinases of Methylobacterium extorquens [44] and H. methylovorum GM2 [33] were examined and shown to form 2-phosphoglycerate. The serine pathway and significant levels of glycerate-2-kinase were also reported in Pseudomonas species grown on methanol as well as oxalate [45-47].

In different strains of Agrobacterium vitis (AB3, AB4), a grapevine pathogen, two plasmid-encoded GK II homologs (ttuD4 (pTrAB4), ttuD3 (pTrAB3)) were identified. The genes are part of the plasmid-encoded tartrate utilization gene clusters. Using a mutational approach, hydroxypyruvate reductase activity was suggested although the catalyzed reaction was unknown $[48,49]$. The tartrate utilization pathway shares common reactions with the serine cycle (conversion of hydroxypyruvate via 2-phosphoglycerate to pyruvate). From the absence of similarities of TtuD to known hydroxypyruvate reductases and the high similarity to glycerate kinase it was already previously suggested that the enzyme encodes glycerate kinase rather than hydroxypyruvate reductase [44]. Therefore, in contrast to annotations found in many genome

Table 3: Characterized and predicted members of the three different glycerate kinase classes

\begin{tabular}{|c|c|c|c|c|}
\hline Glycerate kinase class & Organism & Physiological function; Pathway & Reaction product & Literature \\
\hline \multirow[t]{10}{*}{ GK class II (MOFRL family) } & Archaea & & & \\
\hline & Thermoproteustenax & $\begin{array}{l}\text { Glucose degradation via sugar acids } \\
\text { (gluconate); Branched ED pathway }\end{array}$ & 2-PG & $\begin{array}{c}\text { This manuscript, } \\
{[30,32]}\end{array}$ \\
\hline & Picrophilustorridus & & & \\
\hline & Thermoplsma acidophilum & & & \\
\hline & Bacteria & & & \\
\hline & $\begin{array}{l}\text { Facultative Methylotrophs, } \\
\text { Methylobacterium extorquens } \\
\text { Hyphomicrobium methylovorum }\end{array}$ & $\begin{array}{l}\text { Growth on } \mathrm{Cl} \text {-compounds (e.g. methane, } \\
\text { methanol) and conversion in } \mathrm{C} 3- \\
\text { compounds via hydroxypyruvate; } \\
\text { Assimilatory serine pathway }\end{array}$ & 2-PG & {$[33,44-47]$} \\
\hline & Pseudomonas sp. & $\begin{array}{c}\text { Growth on } \mathrm{Cl} \text { and } \mathrm{C} 2 \text {-compounds (e.g. } \\
\text { methanol, oxalate, glycolate); Serine } \\
\text { pathway \& glyoxylate metabolism' }\end{array}$ & - & \\
\hline & $\begin{array}{l}\text { Agrobacterium vitis (two plasmid-encoded } \\
\text { genes, glycerate kinase instead of } \\
\text { hydroxypyruvate reductase activity } \\
\text { predicted) }\end{array}$ & $\begin{array}{l}\text { Tartrate utilization, shares common } \\
\text { reactions with the serine pathway; } \\
\text { Tartrate utilization pathway }\end{array}$ & 2-PG & {$[48,49]$} \\
\hline & Eukarya & & & \\
\hline & Rat liver, rat kidney cortex & $\begin{array}{l}\text { Gluconeogenesis from serine, fructose } \\
\text { metabolism }\end{array}$ & 2-PG & {$[51-53]$} \\
\hline \multirow[t]{5}{*}{ GK class I } & Bacteria & & & \\
\hline & Escherichia coli (KI2) GK-I & $\begin{array}{l}\text { Allantoin assimilation (purine } \\
\text { degradation); Glycerate pathway }\end{array}$ & 3-PG & {$[55]$} \\
\hline & Escherichia coli (KI2) GK-2 & $\begin{array}{l}\text { Sugar acid degradation; Glucarate/ } \\
\text { galactarate utilization pathway }\end{array}$ & 2-PG & {$[56]$} \\
\hline & Pseudomonas sp. & Growth on sugar or sugar acids I & - & \\
\hline & Flavobacterium strains & $\begin{array}{c}\text { Growth on ethylene glycol; Glycerate } \\
\text { pathway }\end{array}$ & 2-PG & [57] \\
\hline \multirow[t]{3}{*}{ GK class III } & Eukarya & & & \\
\hline & Plant, Arabidopsis thaliana & Photorespiration; C2-cycle & 3-PG & [31] \\
\hline & Fungi, Neurospora crassa & $\begin{array}{c}\text { Growth on glycerol; Oxidative glycerol } \\
\text { metabolism }\end{array}$ & $3-P G$ & {$[58]$} \\
\hline
\end{tabular}




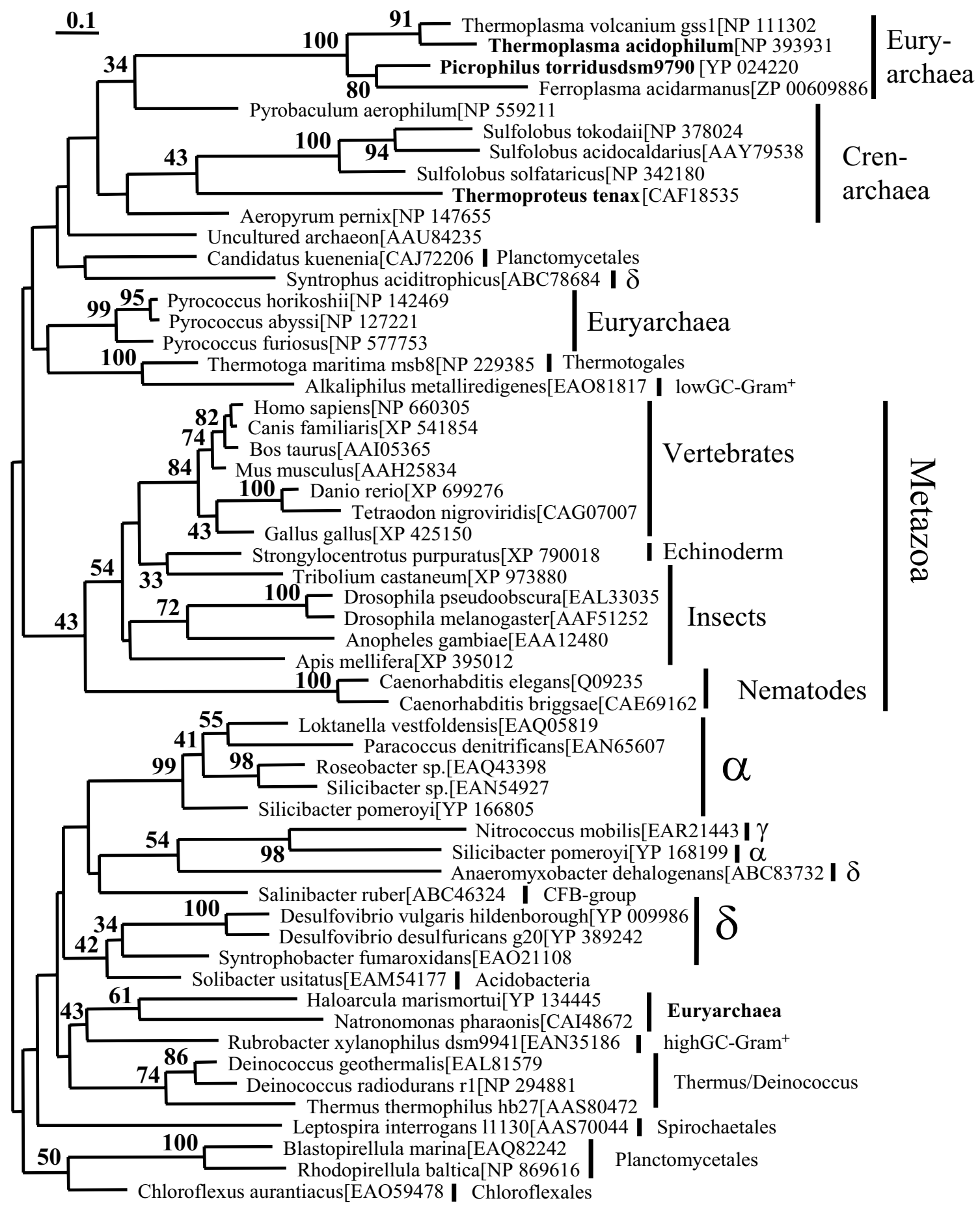

Figure 6

Phylogenetic analyses of class II glycerate kinases (MOFRL family). The best Maximum Likelihood tree based on 56 sequences and 169 positions inferred by the program Treefinder with a WAG $+\Gamma_{4}$ model. Numbers at internal nodes are corresponding to the bootstrap support values obtained in 100 replicates (using the same program and model). Only values above $30 \%$ are indicated. Characterized enzymes are indicated in bold. 


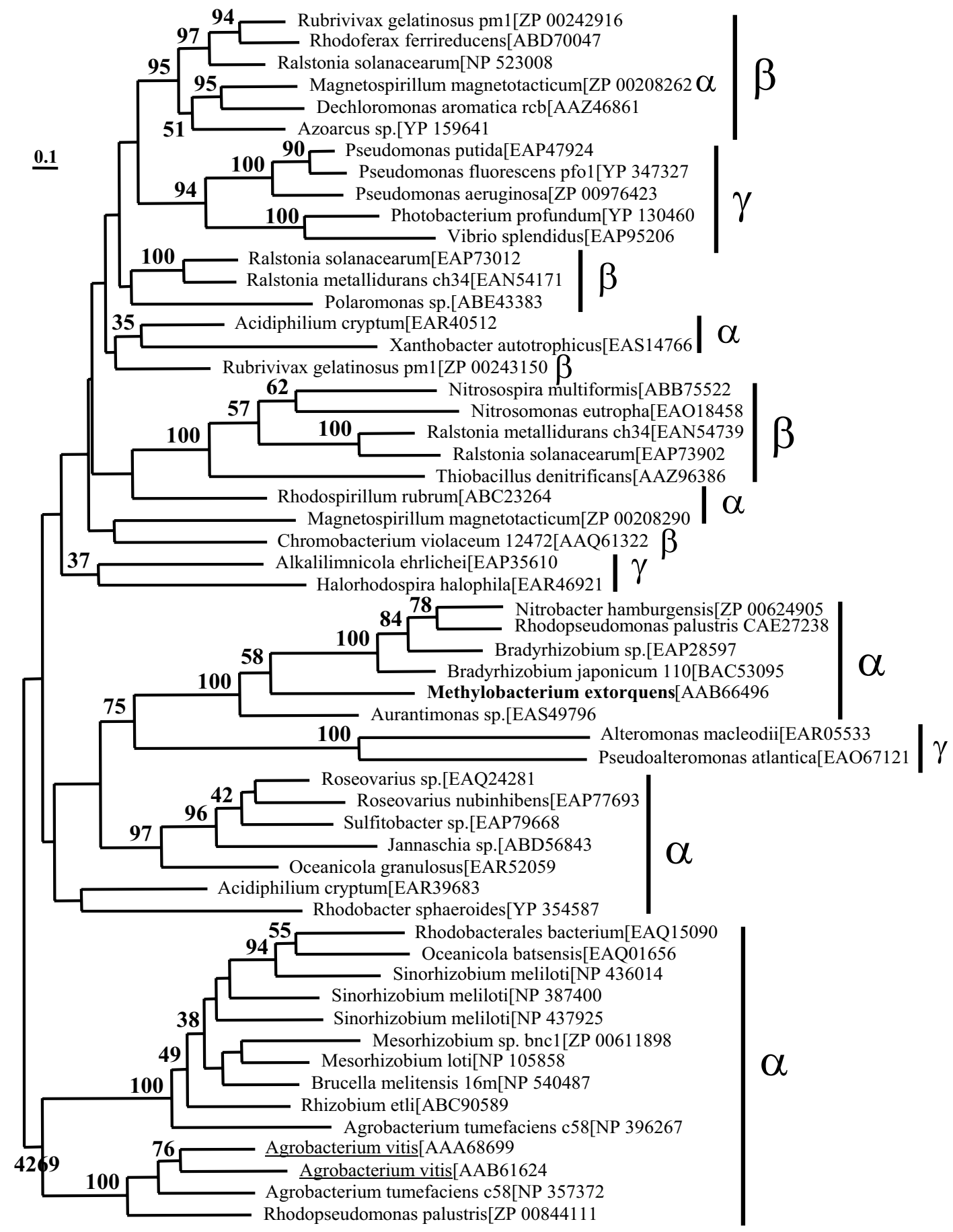

Figure 7

Phylogenetic analyses of class II glycerate kinases (MOFRL family). The best Maximum Likelihood tree based on 56 more closely related proteobacterial sequences $(\alpha-, \beta$ - and $\gamma$-Proteobacteria) and 374 amino acid positions inferred by Treefinder. The MOFRL homologs of Agrobacterium vitis, which were predicted to exhibit hydroxypyruvate reductase activity are underlined. All other manipulations are identical to the one described in Fig. 6. 


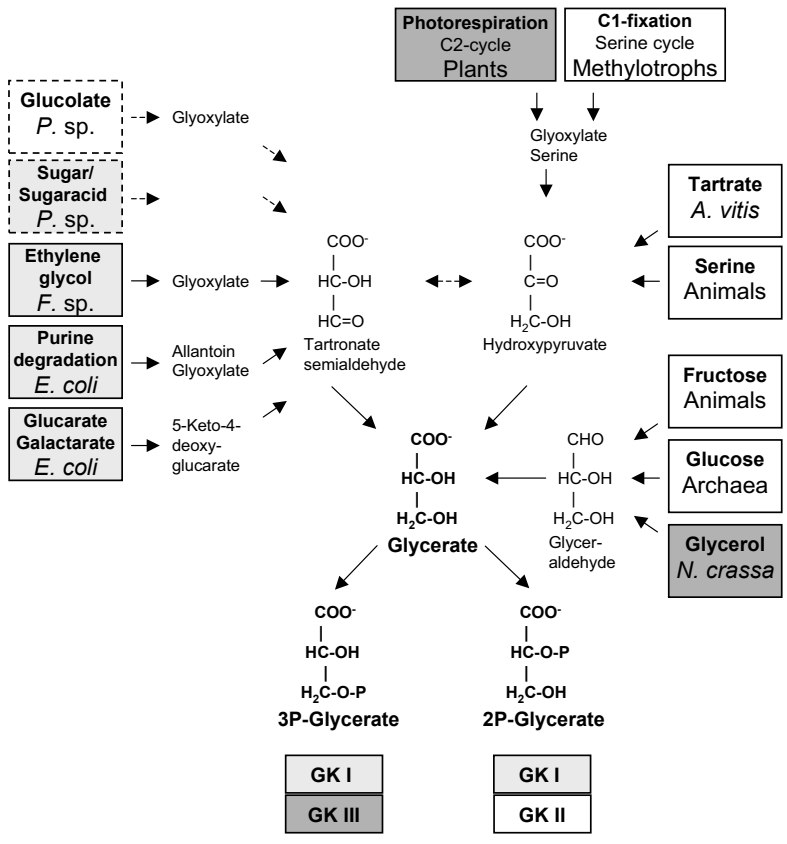

Figure 8

The key role of glycerate kinase in carbohydrate metabolism. Current knowledge about the physiological function of glycerate kinases of the different glycerate kinase classes in extant living organisms is shown (according to Table 3). The different carbon sources/pathways and organisms are boxed and the color indicates the involvement of glycerate kinases of the three different glycerate kinase classes (class II GK (MOFRL family), white; class I GK, light grey; class III GK, dark grey) in the respective metabolic pathway. The formation of 2- or 3-phosphoglycerate is indicated by the name of the enzyme family indicated below the compounds. The suggested function of the class I and class II (MOFRL family) glycerate kinases in Pseudomonas fluorescens and $P$. putida is indicated by dashed lines.

sequencing projects and data banks (COG, SCOP and Pfam), so far only glycerate kinases and no hydroxypyruvate reductases or glycerate dehydrogenases were identified as members of class II glycerate kinases (MOFRL family).

In animals, class II glycerate kinase is the key enzyme for gluconeogenesis from serine and is involved in fructose metabolism [50,51]. Glycerate kinases have been characterized in great detail from different organisms and organs (e.g. rat liver, kidney cortex $[52,53])$ and all enzymes characterized so far were shown to be specific for 2-phosphoglycerate formation. Therefore, all class II glycerate kinases (MOFRL family) characterized until now seem to be specific for 2-phophoglycerate formation.
Members of the classical class I glycerate kinase (GK I) (Pfam 02595; glycerate kinase I (PDB: 1 to6, SCOP)) represent the major glycerate kinase in Bacteria and few Eukarya (220 Bacteria, 7 Eukarya (Entamoeba histolytica (2), Trypanosoma cruzi (2), Fusarium graminearum, Aspergillus nidulans, Dictyostelium discoideum; IPR004381). No homolog was identified in Archaea and animals and only few homologs in $\alpha-$, and $\delta$-Proteobacteria. However, many homologs were found in $\beta$ - and $\gamma$-Proteobacteria as well as low- and high-GC Gram positives. This is nicely complementary since there are almost no Gram positives that harbor class II glycerate kinases (MOFRL enzyme family), whereas the $\alpha$-, and $\delta$-Proteobacteria do contain predominantly members of class II glycerate kinases.

Glycerate kinases have been characterized from different bacterial sources. In E. coli (K12) two different glycerate kinases were identified, which are subject to independent biosynthetic regulation [54]. In more recent studies it was shown that the two glycerate kinases are members of the GK I family (class). The two encoding genes were identified in conserved gene clusters and their involvement in allantoin metabolism (purine degradation via glyoxylate and the glycerate pathway; GK-1, glxK gene, [55]) and glucarate and galactarate utilization (GK-2, gclK gene, [56]) was demonstrated. Both pathways share the conversion of tartronate semialdehyde (TSA) catalyzed by TSA reductase to glycerate and the phosphorylation via glycerate kinase (Fig. 8). Whereas the enzyme involved in sugar acid degradation forms 2-phosphoglycerate, the enzyme of the glycerate pathway forms 3-phosphoglycerate. Phylogenetic analyses indicate that also the Flavobacterium sp. glycerate kinase (Leeuwenhoekiella blandensis MED217, EAQ51383), which was purified from ethylene glycol grown cells and uses the glycerate pathway for conversion to pyruvate via 2-phosphoglycerate [57], is a member of this enzyme family. Therefore, the currently characterized enzymes of the class I glycerate kinases form either 2- or 3-phosphoglycerate.

Members of a novel third glycerate kinase class (named GK class III here) were reported recently (IPR 006083, PF00485, COG 4240 predicted kinases; P-loop-containing NTP hydrolases (PDB: 1a7j, SCOP)) [31]. Detailed phylogenetic analysis revealed a more general distribution in cyanobacteria (e.g. most Synechococcus sp., Prochlorococcus marinus) as well as in proteobacteria, especially of the $\gamma$-group (e.g. Nitrosococcus oceanii, Pseudoalteromonas tunicate) than reported previously (data not shown). Therefore, this enzyme family seems to occur in fungi, plant and few bacteria (i.e. most cyanobacteria and few $\gamma$-proteobacteria). Some of the sequences in the databanks were annotated as phosphoribulokinase/uridine kinase due to the presence of the PRK/UK domain (IPR 006083, Pfam 00485, amino acid 210-425 A. thaliana) and their affilia- 
tion with the diverse phosphoribulokinase/uridine kinase family (see above). Interestingly, in cyanobacteria two Synechococcus strains (JA-2-3B'a (ABD02569), JA-3-3Ab (ABC99586)) as well as Synechocystis sp. Pcc6803 (P73408) possess only a class I glycerate kinase homolog.

The enzymes of Arabidopsis thaliana (At1g80380) and Saccharomyces cerevisiae (NP_011721) were shown to possess glycerate kinase activity and were characterized [31]. Both enzymes are specific for glycerate and form 3-phosphoglycerate. Many plant enzymes were characterized in great detail previously, but the encoding genes were not identified [31,35-38]. In plants, glycerate kinase plays an important role in the photorespiratory $\mathrm{C}-2$ cycle, which compensates for the oxygenase activity of ribulose-1,5bisphosphate carboxylase/oxygenase (RUBISCO) and thus serves as carbon recovery system reconverting 2phosphoglycolate to 3-phosphoglycerate [31]. The C-2 cycle involves at least ten reaction steps localized in different cell organelles (chloroplast, peroxisome, mitochondria). The final step of glycerate phosphorylation is performed in the chloroplast.

In fungi, a role of glycerate kinase was reported in Neurospora crassa grown on glycerol [58], which is metabolized by a phosphorylative pathway via glycerol kinase and an oxidative pathway via NADP+-glycerol dehydrogenase, glyceraldehyde dehydrogenase and glycerate kinase. Phylogenetic analysis revealed only one homolog of the class III glycerate kinases in Neurospora crassa (EAA32802). The function in Bacteria (Cyanobacteria and Proteobacteria) remains unclear and a role in carbon metabolism, as reported for fungi [58], or in photorespiration, as suggested for complex cyanobacteria [31], might be possible.

In summary, phylogenetic analyses of class II (MOFRL), class I and class III glycerate kinases revealed a separated distribution: (i) class II members in Archaea, animals and Bacteria, especially $\alpha-$, $\beta$ - and $\gamma$-Proteobacteria, (ii) class I members in Bacteria (especially Gram positives and $\beta$ and $\gamma$-Proteobacteria, but only few Cyanobacteria) and (iii) members of class III glycerate kinases in plants, fungi, Cyanobacteria and few Proteobacteria (many of the $\gamma$ group). Interestingly, no organism harbors members of all three glycerate kinase classes and only very few comprise members of two different glycerate kinase classes. Pseudomonas fluorescens and P. putida harbor a class II glycerate kinase (MOFRL) homolog as well as the class I glycerate kinase. In addition, few fungi (Coccidioides immintis, Aspergillus nidulans, Giberella zeae) comprise class I and class III glycerate kinase homologs. The physiological role of the different glycerate kinase homologs is still unclear. For the facultatively methylotrophic Pseudomonas species a putative role of the GK class II homolog in C1-fixation as well as glyoxylate metabolism and for the GK class I homolog in sugar/sugar acid degradation might be suggested [45-47] (Tab. 3, Fig. 8). This is supported by the organization of the GK class II gene homolog (PFL1595) in a gene cluster comprising genes encoding pyruvate kinase (PFL1594), tartronate semialdehyde reductase (TSAR) (PFL1596), hydroxypyruvate isomerase (PFL1597) and glyoxylate carboligase (tartronate-semialdehyde synthase) (PFL1598) in Pseudomonas fluorescens (strain Pfo-1 and Pf-5) as well as P. putida. A similar coorganisation of the class II glycerate kinase (MOFRL family) and pyruvate kinase is also reported in M. extorquens and A. vitis and a function in the generation of pyruvate/ acetyl-CoA for anabolic purposes is discussed [44]. The GK class I gene homolog (PFL2908) is found in a gene cluster with a putative transcriptional regulator involved in sugar acid recognition (PFL2909), a putative 2hydroxyacid dehydrogenase (PFL2904) and a putative PfkB family carbohydrate kinase (putative KDG kinase; PFL2902).

As shown in Fig. 8, there seems to be no correlation between the biochemical function or pathway and the enzyme involved from the metabolic point of view. For example, sugar acids (e.g. glucarate) are degraded in E. coli via a class I glycerate kinase and in $T$. tenax glucose degradation via gluconate is performed by a member of class II glycerate kinases. However, these analyses demonstrate that glycerate is a key metabolite in the central carbohydrate metabolism. Glycerate is formed during the degradation of various compounds such as amino acids (serine), sugars (glucose, fructose), sugar acids (glucarate, oxalate, tartrate), glycerol, as well as during the synthesis of C-3 compounds from C-1 (methane, methanol) and C2 (2-phosphoglycolate) compounds. The different metabolic routes merge at the level of the two isomers hydroxypyruvate and tartronate-semialdehyde as well as glyceraldehyde, which are converted to glycerate via redox reactions. Therefore, the conversion of glycerate to 2 - or 3 phosphoglycerate by glycerate kinases of the three different enzyme classes is the key reaction for channeling a great variety of intermediates into the EMP pathway, which serves as funnel for catabolic as well as anabolic purposes. So far, not much is known about the metabolism of carbohydrates other than glucose, galactose and fructose in Archaea. These findings suggest that Archaea share with organisms from other domains of life the common concept that alternative metabolic routes channel into the EMP pathway via the glycerate kinase reaction.

\section{Conclusion}

To our knowledge, this report contains the first characterization of a hyperthermophilic archaeal glycerate kinase. The re-evaluation of available archaeal genome sequence information revealed that the branched Entner-Doudor- 
off (ED) pathway, rather than the suggested non- or semiphosphorylative ED pathway, is common for sugar degradation in Archaea that utilize the ED pathway (with the only exception of Halobacterium spec. NRC-1). Archaeal glycerate kinases are members of the MOFRL (multiorganism fragment with rich leucine) family and in contrast to many current annotations found, so far no hydroxypyruvate reductases or glycerate dehydrogenases were identified as members of this enzyme family. Detailed phylogenetic studies demonstrated the presence of three distinct glycerate kinase classes that share no common origin, and are distributed separately in extant organisms. The affiliation of characterized glycerate kinases with the three different enzyme classes as well as their physiological function gives no evidence to the association with particular pathways. However, our results highlight the key function of glycerate kinase in funneling various substrates into the common EMP pathway for catabolic and anabolic purposes.

\section{Methods}

\section{Strains and growth conditions}

Cultures of T. tenax (DSM 2078, [14] were grown as reported previously [17]. E. coli strains DH5 $\alpha$ (Life Technologies), BL21(DE3) (Novagen) for cloning and expression studies were grown under standard conditions [59] following the instructions of the manufacturer.

\section{(Bio)chemicals and enzymes}

If not indicated otherwise, (bio)chemicals and enzymes were purchased from Sigma-Aldrich, VWR International or Roche Diagnostics $\mathrm{GmbH}$ in analytical grade. $\mathrm{D}$ - and LGlycerate was purchased from Sigma.

\section{Heterologous expression}

For heterologous expression, the pET vector system (pET$24 a$, Novagen) was used. The garK gene coding for the putative glycerate kinase, (TTX_0788, AJ 621345) was cloned into pET-24a via two new restriction sites (NdeI and EcoRI) intoduced by PCR mutagenesis with the primer set Ttx-garK-pETf 5'GTTGCAAGTCGACTACCATATGATAG3' and Ttx-garKpETrev 5'TATACTTGGAATTCCTCCTCC3'. PCR mutagenesis was performed using $P f u$ polymerase (Fermentas) and genomic DNA from T. tenax as template. The sequence of the cloned gene was confirmed by dideoxy sequencing of both strands. Expression of the recombinant enzyme in $E$. coli BL21(DE3) was performed following the instructions of the manufacturer (Novagen).

\section{Protein purification}

Recombinant E. coli cells (10 g wet weight) were suspended in $20 \mathrm{ml}$ of $100 \mathrm{mM}$ HEPES/KOH (pH 7.0) containing $7.5 \mathrm{mM}$ dithiothreitol (buffer A) and passed three times through a French pressure cell at $150 \mathrm{MPa}$. Cell debris and unbroken cells were removed by centrifugation $\left(60000 \times g\right.$ for $30 \mathrm{~min}$ at $\left.4^{\circ} \mathrm{C}\right)$. For enrichment, the resulting crude extract was diluted 1:1 with buffer $\mathrm{A}$ and subjected to a heat precipitatation at $80^{\circ} \mathrm{C}$ for $30 \mathrm{~min}$. After heat precipitation, the sample was cleared by centrifugation $\left(60000 \times \mathrm{g}\right.$ for $30 \mathrm{~min}$ at $\left.4{ }^{\circ} \mathrm{C}\right)$, dialyzed overnight against $50 \mathrm{mM}$ HEPES/KOH ( $\mathrm{pH} 7.0$ ), $7.5 \mathrm{mM}$ dithiothreitol (2-liter volume, $4^{\circ} \mathrm{C}$ ). Enzyme purification was achieved by chromatography on $\mathrm{Q}$ sepharose fast flow (Amersham Biosciences) pre-equilibrated in $50 \mathrm{mM}$ HEPES/KOH (pH 7.0), 7.5 mM dithiothreitol. All glycerate kinase activity was found in the run-through fraction. $\left(\mathrm{NH}_{4}\right)_{2} \mathrm{SO}_{4}$ was added to the protein fraction to a final concentration of $0.7 \mathrm{M}$ and the mixture was applied to a phenyl sepharose (high performance) column (Amersham Biosciences) pre-equilibrated in buffer A containing $0.7 \mathrm{M}\left(\mathrm{NH}_{4}\right)_{2} \mathrm{SO}_{4}$. After three washing steps with buffer A, protein was eluted by a linear gradient of buffer A with increasing concentration of ethylene glycol $(0-100 \%)$. Fractions with glycerate kinase activity were pooled and dialyzed overnight against $50 \mathrm{mM}$ HEPES/KOH (pH 7.0), $7.5 \mathrm{mM}$ dithiothreitol, $300 \mathrm{mM} \mathrm{KCl}$. After concentration by membrane filtration (Vivaspin $6 \mathrm{ml}$ Concentrator, 5000-MWCO PES, Vivascience Sartorius Group) protein was subjected to gel filtration on HiLoad 26/60 Superdex 200 prep grade (Amersham Biosciences) pre-equilibrated in dialysis buffer. Fractions containing the homogeneous enzyme fraction were pooled and used for enzymatic assays. Protein concentration was determined according to Bradford [60] using the reagent kit from BioRad Laboratories (Munich, Germany) and bovine serum albumin as standard. The purity and molecular mass of the subunits of glycerate kinase were examined by SDS-polyacrylamide gel electrophoresis under denaturating conditions according to Laemmli [61] with Dalton Mark VII-L (Sigma) as standard.

\section{Molecular mass determination}

The native molecular mass was determined by gel filtration on a HiLoad 26/60 Superdex 200 prep grade column (Amersham Biosciences) using the same running conditions as for enzyme purification (protein concentration: $0.45 \mathrm{mg}$ protein $/ \mathrm{ml}$ ). Standards: ferritin type I (horse spleen, $443 \mathrm{kDa}$ ), alcohol dehydrogenase (yeast, 148 $\mathrm{kDa}$ ), D-lactate dehydrogenase (Lactobacillus leichmanii, $78 \mathrm{kDa}$ ), and cytochrome c (bovine heart, $12.5 \mathrm{kDa}$ ).

\section{Enzyme assays and determination of kinetic, enzymatic and regulatory properties \\ Glycerate kinase assay}

For the determination of all parameters, except substrate specificity, a discontinuous assay at $70^{\circ} \mathrm{C}$, which monitors the glycerate-dependent formation of 2-phosphoglycerate was used. In the standard assay the phosphorylation of glycerate by ATP was followed by coupling the forma- 
tion of the reaction product 2-phosphoglycerate to the oxidation of NADH via enolase (S. cerevisiae, bakers yeast EC 4.2.1.11), pyruvate kinase (rabbit muscle, EC 2.7.1.40) and lactate dehydrogenase (rabbit muscle, EC 1.1.1.27). The formation of 3-phosphoglycerate was studied by the addition of 1 unit of phosphoglycerate mutase (rabbit muscle, EC 5.4.2.1). The glycerate kinase assay was performed in $100 \mathrm{mM} \mathrm{HEPES} / \mathrm{KOH}\left(\mathrm{pH} 7.5,70^{\circ} \mathrm{C}\right)$ in the presence of glycerate kinase ( $10 \mu \mathrm{g}$ protein/ml volume), 5 $\mathrm{mM}$ ATP and $20 \mathrm{mM} \mathrm{MgCl}_{2}$. The reaction was started by the addition of $0.25 \mathrm{mM}$ D-glycerate. The indicator reaction ( $0.5 \mathrm{ml}$ total volume) was performed at $37^{\circ} \mathrm{C}$ in 100

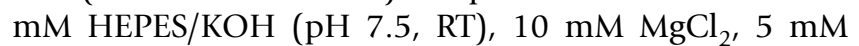
ADP, $0.5 \mathrm{mM} \mathrm{NADH}, 3.5$ units of pyruvate kinase, 2.5 units of lactate dehydrogenase and $100 \mu \mathrm{l}$ aliquots from the glycerate kinase assay. The reaction was started by addition of 1 unit enolase. Enzymatic activities were measured by monitoring the increase in absorption at 340 $\mathrm{nm}\left(\varepsilon_{\mathrm{NADH}}=6.3 \mathrm{mM}^{-1} \mathrm{~cm}^{-1}\right)$. The measured enzyme activity was directly proportional to the amount of enzyme added to the assay. If not stated otherwise, three independent measurements were performed for each assay, and the experimental error is given.

For determination of $\mathrm{K}_{\mathrm{m}}$ - and $\mathrm{V}_{\max }$-values for D-glycerate and ATP, concentration ranges of $0-5 \mathrm{mM}$ and $0-10 \mathrm{mM}$, respectively, in the presence of $20 \mathrm{mM} \mathrm{Mg}^{2+}$ were used. In order to assure the linearity of the enzyme reaction kinetics, reaction times of $0,1,2$ and 3 min were recorded for each measurement. Calculation of the kinetic parameters $\left(\mathrm{V}_{\max }\right.$ and $\left.\mathrm{K}_{\mathrm{m}}\right)$ were performed by iterative curve-fitting (Hill) using the program Origin (Microcal Software Inc.).

Co-substrate specificity was tested by substituting ATP ( 5 $\mathrm{mM}$ ) for alternative phosphoryl donors (CTP, GTP, TTP, UTP, ADP as well as $\mathrm{PP}_{\mathrm{i}}$ and $\mathrm{P}_{3}, \mathrm{P}_{5}$ and $\mathrm{P}_{25}$ polyphoshates) at equimolar concentrations. Measurements were generally performed in the presence of $20 \mathrm{mM} \mathrm{Mg}^{2+}$; for $\mathrm{PP}_{\mathrm{i}}$ and polyphosphate $1 \mathrm{mM} \mathrm{Mg}^{2+}$ was added. Metal ion requirement was analyzed by exchanging $\mathrm{Mg}^{2+}$ for other divalent metal ions and by addition of EDTA. Samples were incubated at $70^{\circ} \mathrm{C}$ for 0 and 3 minutes and ion concentrations of $0.2,2,5$ and $20 \mathrm{mM}$ were tested. EDTA was added at a final concentration of $40 \mathrm{mM}$ in the presence of $20 \mathrm{mM}$ $\mathrm{Mg}^{2+}$. The effects of $\mathrm{K}^{+}$and $\mathrm{NH}_{4}{ }^{+}$were studied at concentrations of $50 \mathrm{mM}$.

For effector studies, activity was determined in the presence of non-saturating concentrations of D-glycerate $(0.05 \mathrm{mM})$ as well as non-saturating $(0.05 \mathrm{mM})$ or saturating $(5 \mathrm{mM})$ concentrations of ATP. Temperature dependence was followed over a wide range of temperatures $\left(30-100^{\circ} \mathrm{C}\right)$ using the standard glycerate kinase assay.
Substrate specificity was measured at $70^{\circ} \mathrm{C}$ in a discontinuous assay by monitoring ADP formation from the ATPdependent phosphorylation of different substrates. ADP formation was coupled to the oxidation of NADH via pyruvate kinase and lactate dehydrogenase. The glycerate kinase assay was performed as described above but in the presence of alternative substrates $(5 \mathrm{mM})$ instead of the $D$ glycerate. The indicator reaction ( $0.5 \mathrm{ml}$ total volume) was performed at $37^{\circ} \mathrm{C}$ in $100 \mathrm{mM} \mathrm{HEPES} / \mathrm{KOH}$ (pH 7.5, $\mathrm{RT}), 10 \mathrm{mM} \mathrm{MgCl}{ }_{2}, 5 \mathrm{mM}$ phosphoenol-pyruvate, 0.5 mM NADH, 3.5 units of pyruvate kinase and 2.5 units of lactate dehydrogenase. The reaction was started by addition of $100 \mu \mathrm{l}$ aliquots from the glycerate kinase assay. Enzymatic activities were determined as described above.

\section{Hydroxypuruvate reductase/glycerate dehydrogenase assay}

Hydroxypyruvate reductase activity was determined at $70^{\circ} \mathrm{C}$ using a continuous assay. The reduction of hydroxypyruvate to glycerate was followed in the presence of $\mathrm{NAD}(\mathrm{P}) \mathrm{H}+\mathrm{H}^{+}$in $100 \mathrm{mM}$ HEPES/KOH $(\mathrm{pH} 7.5, \mathrm{RT})$ including $10 \mathrm{mM}$ hydroxypyruvate, $0.5 \mathrm{mM} \mathrm{NAD}(\mathrm{P}) \mathrm{H}+$ $\mathrm{H}^{+}$and $10 \mu \mathrm{g}$ of protein (assay volume $1 \mathrm{ml}$ ).

\section{Sequence Handling and phylogenetic analyses}

The initial alignments, obtained with CLUSTAL X [62], were manually refined using the ED option of the MUST program package [63]. All data sets were analysed by a Maximum Likelihood (ML) method, implemented in Treefinder [64], with a model based on the Whelan and Goldman (WAG) matrix of amino acid replacements assuming a proportion of invariant positions and gamma distributed rates $(\mathrm{WAG}+\mathrm{F}+\mathrm{I}+\Gamma 4)$. All phylogenetic trees presented are Treefinder ML topologies. Bootstrap analyses with 100 replicates were used to estimate the support for internal nodes of the phylogenies (Treefinder, $\mathrm{WAG}+\mathrm{F}+\mathrm{I}+\mathrm{\Gamma} 4$ model). The bootstrap consensus tree was subsequently generated by the CONSENSE option of the PHYLIP package [65]. PSI Blast analyses were performed using the NCBI browser [66].

\section{Authors' contributions}

DK carried out the cloning, expression, purification and biochemical characterization of the glycerate kinase of $T$. tenax. HA contributed to experimental design, enzyme purification and characterization, data mining (comparative genomics studies) and to the writing process. HB performed all phylogenetic studies. BS conceived of the study, designed and coordinated the study, carried out data mining and prepared the manuscript draft. All authors read and approved the final manuscript.

\section{Acknowledgements}

This work was supported by the Deutsche Forschungsgemeinschaft (SPP II I2, S1642/6-I; SI642/7-I). 


\section{References}

I. Conway T: The Entner-Doudoroff pathway: history, physiology and molecular biology. FEMS Microbiol Rev 1992, 9: I-27.

2. De Rosa M, Gambacorta A, Nicolaus B, Giardina P, Poerio E, Buonocore V: Glucose metabolism in the extreme thermoacidophilic archaebacterium Sulfolobus solfataricus. Biochem J 1984 224:407-4I4.

3. Budgen $\mathrm{N}$, Danson MJ: Metabolism of glucose via a modified Entner-Doudoroff pathway in the thermoacidophilic archaebacterium Thermoplasma acidophilum. FEBS Lett 1986, | 96:207-210.

4. Siebers B, Hensel R: Glucose catabolism of the hyperthermophilic archaeum Thermoproteus tenax. FEMS Microbiol Lett 1993, I I I: I-8.

5. Selig M, Schönheit P: Oxidation of organic compounds to $\mathbf{C O}_{2}$ with sulfur or thiosulfate as electron acceptor in the anaerobic hyperthermophilic archaea Thermoproteus tenax and Pyrobaculum islandicum proceeds via the citric acid cycle. Arch Microbiol 1994, 162:286-294.

6. Siebers B, Wendisch VF, Hensel R: Carbohydrate metabolism in Thermoproteus tenax: in vivo utilization of the non-phosphorylative Entner-Doudoroff pathway and characterization of its first enzyme, glucose dehydrogenase. Arch Microbiol 1997, 168:120-127.

7. Selig M, Xavier KB, Santos H, Schönheit P: Comparative analysis of Embden-Meyerhof and Entner-Doudoroff glycolytic pathways in hyperthermophilic archaea and the bacterium Thermotoga. Arch Microbiol 1997, 167:217-232.

8. Siebers B, Tjaden B, Michalke K, Dörr C, Ahmed H, Zaparty M, Gordon P, Sensen CW, Zibat A, Klenk HP, Schuster SC, Hensel R Reconstruction of the central carbohydrate metabolism of Thermoproteus tenax by use of genomic and biochemical data. J Bacteriol 2004, I 86:2179-2194.

9. Tomlinson GA, Koch TK, Hochstein LI: The metabolism of carbohydrates by extremely halophilic bacteria: glucose metabolism via a modified Entner-Doudoroff pathway. Can J Microbiol 1974, 20:1085-109|.

10. Ahmed H, Ettema TJ, Tjaden B, Geerling ACM, van der Oost J, Siebers $B$ : The semi-phosphorylative Entner-Doudoroff pathway in hyperthermophilic archaea: a re-evaluation. Biochem J 2005, 390:529-540.

II. Siebers B, Schönheit P: Unusual pathways and enzymes of central carbohydrate metabolism in Archaea. Curr Opin Microbiol 2005, 8:695-705.

12. Verhees $\mathrm{CH}$, Kengen SWM, Tuininga JE, Schut GJ, Adams MWW, de Vos WM, van der Oost ]: The unique features of glycolytic pathways in Archaea. Biochem J 2003, 375:231-246.

13. van der Oost J, Siebers B: The glycolytic pathways of Archaea: evolution by tinkering. In Archaea: evolution, physiology and molecular biology Ist edition. Edited by: Garrett RA, Klenk H-P. Blackwell Publishing; 2007:247-260.

14. Zillig W, Stetter KO, Schäfer W, Janekovic D, Wunderl S, Holz I, Palm $P$ : Thermoproteales: a novel type of extremely thermoacidophilic anaerobic archaebacteria isolated from Icelandic solfatares. Zentbl Bakteriol Hyg I Abt Org C I98I, 2:205-227.

15. Fischer F, Zillig W, Stetter KO, Schreiber G: Chemolithoautotrophic metabolism of anaerobic extremely thermophilic archaebacteria. Nature $1983,301: 511-513$.

16. Brunner NA, Brinkmann H, Siebers B, Hensel R: NAD+-dependent glyceraldehyde-3-phosphate dehydrogenase from Thermoproteus tenax. The first identified archaeal member of the aldehyde dehydrogenase superfamily is a glycolytic enzyme with unusual regulatory properties. I Biol Chem 1998, 273:6|49-6156.

17. Brunner NA, Siebers B, Hensel R: Role of two different glyceraldehyde-3-phosphate dehydrogenases in controlling the reversible Embden-Meyerhof-Parnas pathway in Thermoproteus tenax: regulation on protein and transcript level. Extremophiles 2001, 5:101-109.

18. Ettema TJ, Ahmed H, Geerling AC, van der Oost J, Siebers B: The non-phosphorylating glyceraldehyde-3-phosphate dehydrogenase (GAPN) of Sulfolobus solfataricus: a key-enzyme of the semi-phosphorylative branch of the Entner-Doudoroff pathway. Extremophiles in press.

19. Reher M, Schönheit P: Glyceraldehyde dehydrogenases from the thermoacidophilic euryarchaeota Picrophilus torridus and
Thermoplasma acidophilum, key enzymes of the non-phosphorylative Entner-Doudoroff pathway, constitute a novel enzyme family within the aldehyde dehydrogenase superfamily. FEBS Lett 2006, 580: I 198-1204.

20. Jung JH, Lee SB: Identification and characterization of Thermoplasma acidophilum glyceraldehyde dehydrogenase: a new class of NADP+ ${ }^{+}$-specific aldehyde dehydrogenase. Biochem J 2006, 397:131-138.

21. Mukund S, Adams MW: The novel tungsten-iron-sulfur protein of the hyperthermophilic archaebacterium, Pyrococcus furiosus, is an aldehyde ferredoxin oxidoreductase. Evidence for its participation in a unique glycolytic pathway. I Biol Chem 1991, 266: 14208-14216.

22. Schicho RN, Snowden LJ, Mukund S, Park JB, Adams MWW, Kelly RM: Influence of tungsten on metabolic patterns in Pyrococcus furiosus, a hyperthermophilic Archaeon. Arch Microbiol 1993, I 59:380-385.

23. Kardinahl S, Schmidt CL, Hansen T, Anemüller S, Petersen A, Schäfer $\mathrm{G}$ : The strict molybdate-dependence of glucose-degradation by the thermoacidophile Sulfolobus acidocaldarius reveals the first crenarchaeotic molybdenum containing enzyme - an aldehyde oxidoreductase. Eur J Biochem 1999, 260:540-548.

24. Lamble HJ, Heyer NI, Bull SD, Hough DW, Danson MJ: Metabolic pathway promiscuity in the archaeon Sulfolobus solfataricus revealed by studies on glucose dehydrogenase and 2-keto-3deoxygluconate aldolase. J Biol Chem 2003, 278:34066-34072.

25. Milburn CC, Lamble HJ, Theodossis A, Bull SD, Hough DW, Danson M], Taylor GL: The structural basis of substrate promiscuity in glucose dehydrogenase from the hyperthermophilic archaeon Sulfolobus solfataricus. J Biol Chem 2006, 28I: | 4796-|4804.

26. Lamble HJ, Milburn CC, Taylor GL, Hough DW, Danson MJ: Gluconate dehydratase from the promiscuous Entner-Doudoroff pathway in Sulfolobus solfataricus. FEBS Lett 2004, 576: I33-I36.

27. Kim S, Lee SB: Identification and characterization of Sulfolobus solfataricus D-gluconate dehydratase: a key enzyme in the non-phosphorylated Entner-Doudoroff pathway. Biochem J 2005, 387:27I-280.

28. Theodossis A, Walden H, Westwick EJ, Connaris H, Lamble HJ, Hough DW, Danson MJ, Taylor G: The structural basis for substrate promiscuity in 2-keto-3-deoxygluconate aldolase from the Entner-Doudoroff pathway in Sulfolobus solfataricus. J Biol Chem 2004, 279:43886-43892

29. Lamble HJ, Theodossis A, Milburn CC, Taylor GL, Bull SD, Hough DW, Danson MJ: Promiscuity in the part-phosphorylative Entner-Doudoroff pathway of the archaeon Sulfolobus solfataricus. FEBS Lett 2005, 579:6865-6869.

30. Noh M, Jung JH, Lee SB: Purification and characterization of glycerate kinase from the thermoacidophilic Archaeon Thermoplasma acidophilum: An enzyme belonging to the second glycerate kinase family. Biotechnol Bioprocess Eng 2006, I I:344-350.

31. Boldt R, Edner C, Kolukisaoglu U, Hagemann M, Weckwerth W, Wienkoop S, Morgenthal K, Bauwe H: D-glycerate 3-kinase, the last unknown enzyme in the photorespiratory cycle in Arabidopsis, belongs to a novel kinase family. Plant Cell 2005 , I 7:2413-2420.

32. Reher $M$, Bott $M$, Schönheit $P$ : Characterization of glycerate kinase (2-phosphoglycerate forming), a key enzyme of the nonphosphorylative Entner-Doudoroff pathway, from the thermoacidophilic euryarchaeon Picrophilus torridus. FEMS Microbiol Lett 2006, 259: I I3-II9.

33. Yoshida T, Fukuta K, Mitsunaga T, Yamada H, Izumi Y: Purification and characterization of glycerate kinase from a serine-producing methylotroph, Hyphomicrobium methylovorum GM2. Eur J Biochem 1992, 2 1 0:849-854.

34. Schwarzenbacher R, McMullan D, Krishna SS, $X_{u} \mathrm{Q}$, Miller MD, Canaves JM, Elsliger MA, Floyd R, Grzechnik SK, Jaroszewski L, Klock HE, Koesema E, Kovarik JS, Kreusch A, Kuhn P, McPhillips TM, Morse AT, Quijano K, Spraggon G, Stevens RC, van den Bedem H, Wolf G, Hodgson KO, Wooley J, Deacon AM, Godzik A, Lesley SA, Wilson IA: Crystal structure of a glycerate kinase (TMI585) from Thermotoga maritima at 2.70 A resolution reveals a new fold. Proteins 2006, 65:243-248. 
35. Saharan MMR, Singh R: Partial purification and characterization of glycerate kinase from immature pods of Brassica campestris. Plant Physiol Biochem 1993, 3 I:559-566.

36. Kleczkowski LA, Randall DD: Purification and partial characterization of spinach leaf glycerate kinase. FEBS Lett 1983, I 58:3|3-3|6.

37. Chaguturu R: Glycerate kinase from spanish leaves: Partial purification, characterization and subcellular localization. Physiologia plantarum 1985, 63:19-24.

38. Schmitt MR, Edwards GE: Glycerate kinase from leaves of C3 plants. Arch Biochem Biophys I983, 224:332-34I.

39. Jung $\mathrm{JH}$, Lee SB: Identification and characterization of Thermoplasma acidophilum 2-keto-3-deoxy-D-gluconate kinase: A new class of sugar kinases. Biotechnol Bioprocess Eng 2005, 1 0:535-539.

40. Jonassen I, Collins JF, Higgins DG: Finding flexible patterns in unaligned protein sequences. Protein Sci 1995, 4: I587-I595

4I. Jonassen I: Efficient discovery of conserved patterns using a pattern graph. Comput Appl Biosci 1997, I3:509-522.

42. Nelson KE, Clayton RA, Gill SR, Gwinn ML, Dodson RJ, Haft DH, Hickey EK, Peterson JD, Nelson WC, Ketchum KA, McDonald L, Utterback TR, Malek JA, Linher KD, Garrett MM, Stewart AM, Cotton MD, Pratt MS, Phillips CA, Richardson D, Heidelberg J, Sutton GG, Fleischmann RD, Eisen JA, White O, Salzberg SL, Smith HO, Venter JC, Fraser CM: Evidence for lateral gene transfer between Archaea and bacteria from genome sequence of Thermotoga maritima. Nature 1999, 399:323-329.

43. Aravind L, lyer LM, Leipe DD, Koonin EV: A novel family of P-loop NTPases with an unusual phyletic distribution and transmembrane segments inserted within the NTPase domain. Genome Biol 2004, 5:R30.

44. Chistoserdova L, Lidstrom ME: Identification and mutation of a gene required for glycerate kinase activity from a facultative methylotroph, Methylobacterium extorquens AMI. J Bacteriol 1997, I 79:4946-4948.

45. Kornberg HL, Gotto AM: The metabolism of $\mathbf{C 2}$ compounds in micro-organisms. Biochem J I96I, 78:69-82.

46. Anthony C, Dunstan PM, Drabble WT: Metabolism of C I and C 2 compounds by Pseudomonas AMI: a glycerate kinase mutant and a mutant defective in glyoxylate formation from C I compounds. Biochem J I 97I, I25:66P-67P

47. McNerney $\mathrm{T}, \mathrm{O}$ 'Connor ML: Regulation of enzymes associated with C-I metabolism in three facultative methylotrophs. Appl Environ Microbiol 1980, 40:370-375.

48. Crouzet $P$, Otten L: Sequence and mutational analysis of a tartrate utilization operon from Agrobacterium vitis. J Bacterio 1995, I 77:6518-6526.

49. Salomone JY, Crouzet P, De Ruffray P, Otten L: Characterization and distribution of tartrate utilization genes in the grapevine pathogen Agrobacterium vitis. Mol Plant Microbe Interact 1996 9:401-408.

50. Van Schaftingen E: D-glycerate kinase deficiency as a cause of D-glyceric aciduria. FEBS Lett |989, 243:|27-|3|.

5I. Hagopian K, Ramsey JJ, Weindruch R: Serine utilization in mouse liver: influence of caloric restriction and aging. FEBS Lett 2005 579:2009-20I3.

52. Katayama H, Kitagawa $\mathrm{Y}$, Sugimoto E: Purification of rat liver glycerate kinase and studies of its enzymatic and immunological properties. J Biochem (Tokyo) 1980, 88:765-773.

53. Katayama H, Kitagawa $\mathrm{Y}$, Sugimoto E: Role of glucagon in increase of hepatic glycerate kinase of adult and neonatal rats. J Biochem (Tokyo) 1983, 93:1669-1675.

54. Ornston MK, Ornston LN: Two forms of D-glycerate kinase in Escherichia coli. J Bacteriol 1969, 97:|227-|233.

55. Cusa E, Obradors N, Baldoma L, Badia J, Aguilar J: Genetic analysis of a chromosomal region containing genes required for assimilation of allantoin nitrogen and linked glyoxylate metabolism in Escherichia coli. J Bacteriol 1999, I 8 I:7479-7484.

56. Hubbard BK, Koch M, Palmer DRJ, Babbitt PC, Gerlt JA: Evolution of enzymatic activities in the enolase superfamily: Characterization of the (D)-glucarate/galactarate catabolic pathway in Escherichia coli. Biochemistry |998, 37:|4369-|4375.

57. Willetts A: Purification and characterization of glycerate kinase from Flavobacterium sp. N.C.I.B. I I I 7 I [proceedings]. Biochem Soc Trans 1978, 6:565-568.
58. Tom GD, Viswanath-Reddy M, Howe HB: Effect of carbon source on enzymes involved in glycerol metabolism in Neurospora crassa. Arch Microbiol 1978, I I 7:259-263.

59. Sambrook J, Fritsch EF, Maniatis T: Molecular Cloning - A Laboratory Manual 2nd edition. Cold Spring Habour Laboratory Press, New York; 1989

60. Bradford MM: A rapid and sensitive method for the quantitation of microgram quantities of protein utilizing the principle of protein-dye binding. Anal Biochem 1976, 72:248-254.

6I. Laemmli UK: Cleavage of structural proteins during the assembly of the head of bacteriophage T4. Nature 1970 , 227:680-685

62. Thompson JD, Higgins DG, Gibson TJ: CLUSTAL W: improving the sensitivity of progressive multiple sequence alignment through sequence weighting, position-specific gap penalties and weight matrix choice. Nucleic Acids Res 1994, 22:4673-4680.

63. Philippe H: MUST, a computer package of management utilities for sequences and trees. Nucleic Acids Res 1993 2 I:5264-5272.

64. Jobb G, von Haeseler A, Strimmer K: TREEFINDER: a powerful graphical analysis environment for molecular phylogenetics. BMC Evol Biol 2004, 4: 18

65. Felsenstein J: [http://evolution.genetics.washington.edu/phylip.html]

66. Blast: Basic Local Alignment and Search Tool [http:// www.ncbi.nlm.nih.gov]

67. Markowitz VM, Korzeniewski F, Palaniappan K, Szeto E, Werner G Padki A, Zhao X, Dubchak I, Hugenholtz P, Anderson I, Lykidis A, Mavromatis K, Ivanova N, Kyrpides NC: The integrated microbial genomes (IMG) system. Nucleic Acids Res 2006, 34:D344-D348.

Publish with Biomed Central and every scientist can read your work free of charge

"BioMed Central will be the most significant development for disseminating the results of biomedical research in our lifetime. "

Sir Paul Nurse, Cancer Research UK

Your research papers will be:

- available free of charge to the entire biomedical community

- peer reviewed and published immediately upon acceptance

- cited in PubMed and archived on PubMed Central

- yours - you keep the copyright 